\title{
Effects of Silicon, Chromium, and Copper on Kinetic Parameters of Precipitation during Tempering of Medium Carbon Steels
}

\author{
Aleksandr Gokhman ${ }^{1}$, Zbyšek Nový ${ }^{1}$, Pavel Salvetr ${ }^{1, * \mathbb{D}}$, Vasyl Ryukhtin ${ }^{2}{ }^{\mathbb{D}}$, Pavel Strunz $^{2} \mathbb{D}$, Petr Motyčka $^{1}$, \\ Jan Zmeko ${ }^{1}$ and Jakub Kotous ${ }^{1}$
}

check for

updates

Citation: Gokhman, A.; Nový, Z.; Salvetr, P.; Ryukhtin, V.; Strunz, P.; Motyčka, P.; Zmeko, J.; Kotous, J. Effects of Silicon, Chromium, and Copper on Kinetic Parameters of Precipitation during Tempering of Medium Carbon Steels. Materials 2021, 14, 1445. https://doi.org/ $10.3390 /$ ma14061445

Academic Editor: Andrey Belyakov

Received: 23 February 2021

Accepted: 11 March 2021

Published: 16 March 2021

Publisher's Note: MDPI stays neutral with regard to jurisdictional claims in published maps and institutional affiliations.

Copyright: (c) 2021 by the authors. Licensee MDPI, Basel, Switzerland. This article is an open access article distributed under the terms and conditions of the Creative Commons Attribution (CC BY) license (https:/ / creativecommons.org/licenses/by/ $4.0 /)$.
1 COMTES FHT a.s., Prumyslova 995, 33441 Dobrany, Czech Republic; aleksandr.gokhman@comtesfht.cz (A.G.); zbysek.novy@comtesfht.cz (Z.N.); petr.motycka@comtesfht.cz (P.M.); jan.zmeko@comtesfht.cz (J.Z.); jakub.kotous@comtesfht.cz (J.K.)

2 Nuclear Physics Institute, Czech Academy of Sciences, 25068 Řež, Czech Republic; ryukhtin@ujf.cas.cz (V.R.); strunz@ujf.cas.cz (P.S.)

* Correspondence: pavel.salvetr@comtesfht.cz; Tel.: +420-605-843-656

\begin{abstract}
Understanding the tempering behavior of medium carbon steels is mandatory if their mechanical properties are to be improved. For an optimal technology to be developed for this purpose, a substantial experimental basis is needed to extract quantitative information on the microstructure of the tempered material. This paper reports on the characterization of microstructural changes induced by tempering in medium-carbon steels alloyed with $\mathrm{Si}, \mathrm{Cr}, \mathrm{Cu}$, and $\mathrm{Mn}$ using state-ofthe-art experimental techniques. Complementarities among these techniques are highlighted. The evolution of transition carbides, cementite, and copper precipitates is described using data from X-ray diffraction, small and ultra-small angle neutron diffraction, transmission electron microscopy, and dilatometry observation. The effects of silicon, chromium, and copper on the mechanism of carbide and copper precipitation are discussed. The considerable changes found in the size and volume of copper precipitates correlate well with the difference in the yield stress between tempered steels with and without copper.
\end{abstract}

Keywords: medium carbon steels; microstructure; tempering; XRD; TEM; USANS; SANS; dilatometry; carbides; copper precipitates

\section{Introduction}

The use of experimental techniques for characterizing the microstructure of mediumcarbon alloyed with $\mathrm{Si}, \mathrm{Cr}, \mathrm{Cu}$, and $\mathrm{Mn}$ steel contributes to the understanding of the kinetics of precipitation induced by heat treatment. These steels are used in a wide range of applications, e.g., as spring materials. They are characterized by an excellent combination of tensile strength, yield strength, elongation, and reduction of area [1-3]. Typically, their yield strength increases with tempering temperature within a specific temperature range. Reduction of area dramatically increases during tempering from the room temperature (RT) to $300{ }^{\circ} \mathrm{C}$. Any further increase in the tempering temperature leads to a decreasing yield strength and a slow increase in the reduction of area and elongation, up to at least $400{ }^{\circ} \mathrm{C}$ [2]. Tempering after quenching has an important effect on the final properties. Tempering activates migration of carbon from supersaturated martensite. Free carbon plays a key role in each tempering stage, including carbon clustering, precipitation of $\varepsilon$-carbide, retained austenite decomposition, and precipitation of other tempering products such as cementite, carbides of alloying elements and others [4-6]. Besides carbide-based precipitates, intermetallic particles, or pure metal particles, namely copper, which form during tempering seem to be an effective means of strengthening for some types of steels. The mechanism of carbide and copper precipitation during continuous tempering was investigated in copper-bearing medium carbon steel Fe-0.44C-0.60Mn-0.21Si-0.11Cr-1.53Cu 
( $w t^{\%} \%$ in $[7,8]$ by $X$-ray diffraction (XRD), electrical resistivity measurement, small angle neutron scattering (SANS), transmission electron microscopy (TEM), and dilatometry. However, the effects of silicon which counters segregation and the segregating chromium, which are related to the mechanism of tempering [9], have not yet been investigated using a comprehensive study comparable to [7,8]. The main goal of this paper is to report on microstructure characterization of the tempered condition in medium carbon steels with copper and without copper and with higher silicon and chromium levels than in $[7,8]$, based on a combined study by XRD, TEM, dilatometry, SANS, and ultra-small angle neutron scattering (USANS). The materials and methods are outlined in Section 2. Section 3 is devoted to the data obtained from each individual technique. The data are compiled in Section 4 to provide a coherent picture of the tempering process and the effects of the tempering temperature and chemical composition on the mechanism of carbide and copper precipitation.

\section{Materials and Methods}

\subsection{Materials and Heat Treatment}

The material under investigation was medium carbon steel, which is widely used for making springs. Two variants were compared. The first one was $42 \mathrm{SiCr}$ steel and the second was $42 \mathrm{SiCr}+\mathrm{Cu}$ steel, which was substantially modified by an addition of copper. Both variants were made at the company COMTES FHT a.s. Their chemical compositions are given in Table 1. These steels have higher contents of silicon and chromium than Fe-0.44C-0.75Mn-0.25Si-0.03Cr steel and Fe-0.44C-0.60Mn-0.21Si-0.11Cr-1.50Cu steel which were studied in $[7,8]$.

Table 1. Chemical composition of medium carbon steels in the present study (wt\%).

\begin{tabular}{ccccccccccccc}
\hline Steel & $\mathbf{C}$ & $\mathbf{S i}$ & $\mathbf{M n}$ & $\mathbf{P}$ & $\mathbf{S}$ & $\mathbf{C r}$ & $\mathbf{M o}$ & $\mathbf{N i}$ & $\mathbf{C u}$ & $\mathbf{T i}$ & $\mathbf{V}$ & $\mathbf{F e}$ \\
\hline $42 \mathrm{SiCr}$ & 0.39 & 2.02 & 0.65 & 0.011 & 0.003 & 1.21 & 0.03 & 0.07 & 0.09 & 0.004 & 0.012 & bal. \\
$42 \mathrm{SiCr}+\mathrm{Cu}$ & 0.41 & 2.40 & 0.65 & 0.011 & 0.003 & 1.34 & 0.03 & 0.07 & 1.50 & 0.004 & 0.012 & bal. \\
\hline
\end{tabular}

The steels were melted in a vacuum induction furnace and cast into $45 \mathrm{~kg}$ ingots. The ingots were forged to $60 \mathrm{~mm} \times 60 \mathrm{~mm} \times 500 \mathrm{~mm}$ from the temperature of $1100{ }^{\circ} \mathrm{C}$, then reheated to $1100{ }^{\circ} \mathrm{C}$ and hot-rolled to $16.5 \mathrm{~mm} \times 94 \mathrm{~mm} \times 1850 \mathrm{~mm}$, which was followed by slow cooling. The highest temperature was $1100{ }^{\circ} \mathrm{C}$. Finally, rods $13 \mathrm{~mm}$ in diameter and $130 \mathrm{~mm}$ in length were produced.

Specimens were made and induction heated to the austenitizing temperature of $980^{\circ} \mathrm{C}$ for $10 \mathrm{~s}$, quenched in a water bath, and then tempered at $200^{\circ} \mathrm{C}, 400^{\circ} \mathrm{C}$, and $500{ }^{\circ} \mathrm{C}$ for two hours in an electrical chamber furnace, then air-cooled (identified below as 722, 742, and 752 for $42 \mathrm{SiCr}$ steel and 822,842 , and 852 for $42 \mathrm{SiCr}+\mathrm{Cu}$ steel). The process of quenching and tempering is shown in Figure 1.

\subsection{XRD Measurement}

Samples for XRD measurement were prepared by polishing and etching in hydrochloric acid for $90 \mathrm{~s}$ to remove the surface layer formed during polishing. XRD measurements were performed using BRUKER D8 DISCOVER diffractometer (Bruker AXS GmbH, Karlsruhe, Germany) with $1.5406 \AA$ wave length of $\mathrm{Cu}-\mathrm{K} \alpha$ radiation. The scanning angle (2Theta) ranged from $35^{\circ}$ to $105^{\circ}$ with a step size of $0.15^{\circ}$ and a measurement time per step of $0.25 \mathrm{~s}$. A Pseudo-Voigt profile was used for determining the full width half maximum (FWHM) according to [10]. Then the dislocation density and microstrain were calculated according to [11]. 


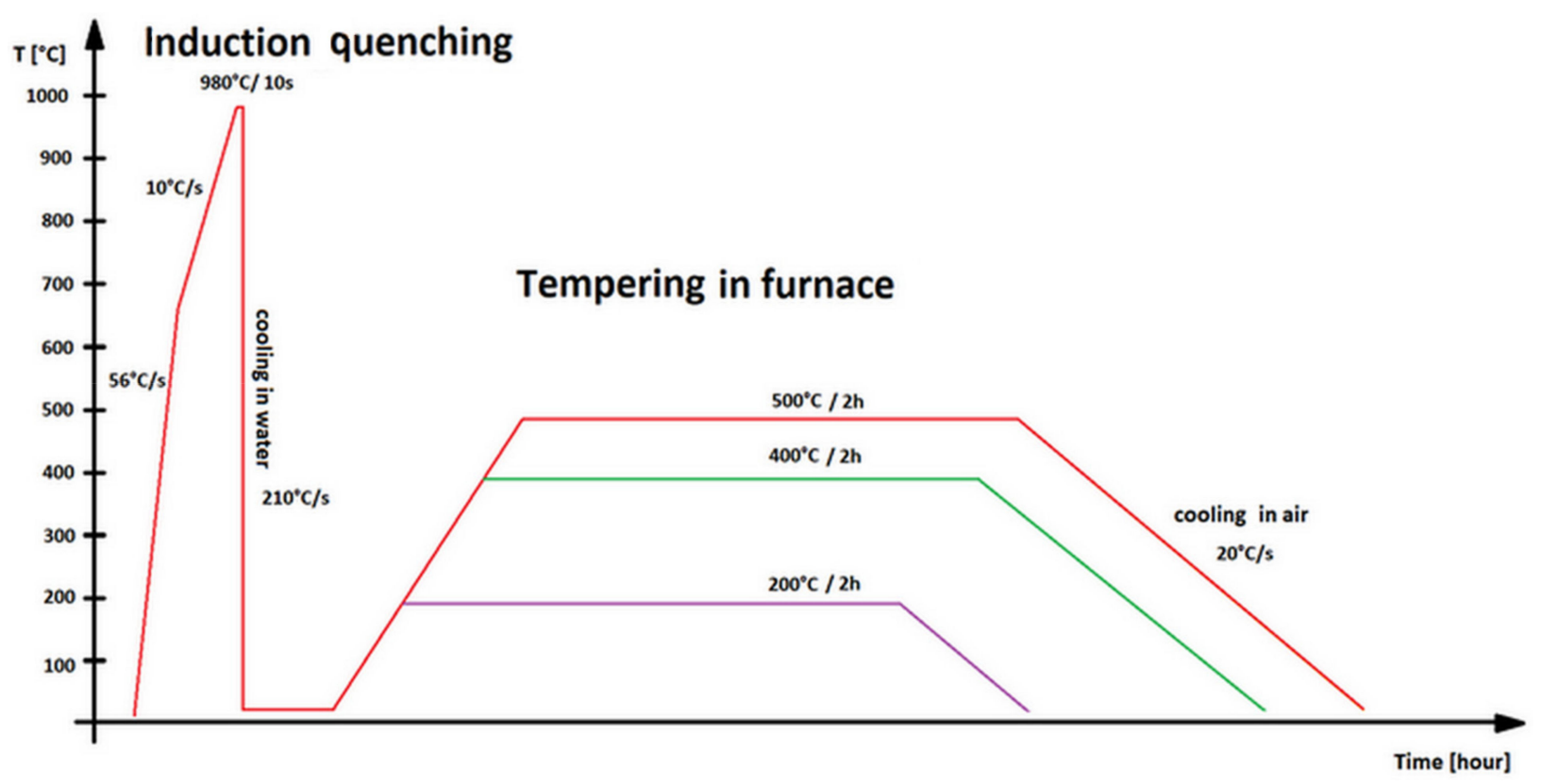

Figure 1. Time-temperature profile of the quenching and tempering process.

\subsection{TEM Observation}

Metallographic samples were prepared by mechanical grinding and polishing of a surface oriented in the longitudinal direction. In order to analyze the precipitates, the samples were quenched and tempered at $200{ }^{\circ} \mathrm{C}, 400{ }^{\circ} \mathrm{C}$, or $500^{\circ} \mathrm{C}$ for $2 \mathrm{~h}$ and examined in transmission electron microscope Jeol $2100 \mathrm{~F}$ (JEOL, Tokyo, Japan accelerating voltage $200 \mathrm{kV}$ ) equipped with an energy dispersive X-ray spectrometer Oxford Instruments XMax80 (Oxford Instruments, High Wycombe, UK) and Aztec software (Oxford Instruments, High Wycombe, UK). The types of precipitates were determined using selected area electron diffraction (SAED) and fast Fourier transform (FFT) of HRTEM images. The size of the precipitates formed during tempering was determined by NIS-elements image analysis software (AR, Laboratory Imaging, Prague, Czech Republic).

The preparation of carbon extraction replicas on $\mathrm{Ni}$ and $\mathrm{Cu}$ grids included the following steps: mechanical and electrochemical polishing, etching with 3\% Nital solution, carbon deposition, etching with $10 \%$ Nital solution, and releasing the carbon replicas with particles electrolytically using a solution of $450 \mathrm{~mL}$ glacial acetic acid, $40 \mathrm{~mL}$ perchloric acid, and $10 \mathrm{~mL}$ distilled water using a voltage of $30 \mathrm{~V}$. The carbon replicas were placed on $\mathrm{Cu}$ and Ni-grids. Thin foils were prepared by focused ion $(\mathrm{Ga})$ beam in scanning electron microscope TESCAN LYRA3 (Tescan, Brno, Czech Republic).

\subsection{Dilatometry}

Specimens with $4 \mathrm{~mm}$ in diameter and $10 \mathrm{~mm}$ in length, which were quenched after austenitization at $980^{\circ} \mathrm{C}$ for $10 \mathrm{~s}$ at cooling rate $100 \mathrm{~K} / \mathrm{s}$ were used for the dilatometry. Then the length decrease due to precipitation was recorded using two push-rod dilatometers at continuous heating at various heating rates. The dilatometer L75PT (Linseis, Selb, Germany) with samples heated in a furnace was used for heating at lower heating rates, the quenching dilatometer L78RITA (Linseis) was used for quenching and heating at $0.1 \mathrm{~K} / \mathrm{s}$ and higher heating rates. Experiments were performed under pure nitrogen, specimens were held in quartz glass push-rods with contact force of $0.3 \mathrm{~N}$.

Non-isothermal tempering was performed using continuous heating with heating rates $\beta=0.003 \mathrm{~K} / \mathrm{s}, 0.01 \mathrm{~K} / \mathrm{s}, 0.05 \mathrm{~K} / \mathrm{s}, 0.1 \mathrm{~K} / \mathrm{s}, 0.5 \mathrm{~K} / \mathrm{s}, 1 \mathrm{~K} / \mathrm{s}, 10 \mathrm{~K} / \mathrm{s}$, and $50 \mathrm{~K} / \mathrm{s}$. The activation energy $E$ and frequency factor $K_{0}$ for the precipitation of carbides were calculated 
for the two stages of tempering for $42 \mathrm{SiCr}$ and $42 \mathrm{SiCr}+\mathrm{Cu}$ steels using an approximate expression from [12]:

$$
\operatorname{Ln} \frac{\beta}{T_{i}^{2}}=-\frac{E}{R T_{i}}+\operatorname{Ln} \frac{R K_{0}}{E}
$$

Here, $R$ is the gas constant, $T_{\mathrm{i}}$ indicates the inflection point in the dilatometer records obtained at various heating rates.

\subsection{USANS and SANS Measurements}

USANS data were collected at CANAM infrastructure in Nuclear Physics Institute of the Czech Academy of Sciences in Řež using a MAUD instrument [13] with several instrumental resolutions at a neutron wavelength of $2.09 \AA$. The samples were placed in a permanent horizontal magnetic field of about $1 \mathrm{~T}$ in order to minimize scattering from magnetic domains.

Pin-hole SANS measurements were performed using V4 instrument at Helmholtz Zentrum Berlin (HZB), Germany [14]. With this conventional SANS technique, one can analyze much finer microstructures (down to $\mathrm{nm}$ scale) than USANS, due to a larger scattering vector magnitude $Q(Q=4 \pi \sin (\theta) / \lambda$, where $2 \theta$ is the scattering angle, $\lambda$ is the neutron wavelength; $\lambda=0.5 \mathrm{~nm}$ was used). The samples were placed in horizontal magnetic field of $2 \mathrm{~T}$ for the measurements. This enables nuclear and magnetic scattering contributions to be separated as shown in [15]. The data were collected using a 2D position sensitive detector. Combining several measurements with sample-to-detector distances of $1.7 \mathrm{~m}, 8 \mathrm{~m}$, and $16 \mathrm{~m}$, the measured SANS data covered a $Q$-range of $0.03-3 \mathrm{~nm}^{-1}$. The raw data were processed according to standard procedure BerSANS [16] for SANS. SASProFit software [17] was used for the USANS data fitting. It should be noted that the USANS data were measured using a slit geometry, whereas the SANS data were collected with pin-hole geometry. It is therefore impermissible to join the datasets from SANS and USANS facilities directly.

\section{Results}

\subsection{XRD}

XRD patterns of quenched $42 \mathrm{SiCr}$ and $42 \mathrm{SiCr}+\mathrm{Cu}$ steels were found to be very similar (Figure 2). Diffraction peaks of $\alpha^{\prime}$ martensite were detected. A weak peak of $\theta$ cementite was found as well. No retained austenite (RA) was detected, which is in line with the relatively high martensite start $\left(M_{S}\right)$ temperatures: $368.4^{\circ} \mathrm{C}$ for $42 \mathrm{SiCr}$ steel and $338.6{ }^{\circ} \mathrm{C}$ for $42 \mathrm{SiCr}+\mathrm{Cu}$ steel. The $M_{s}$ temperatures were calculated using the following equation [18]:

$$
M_{s}\left({ }^{\circ} \mathrm{C}\right)=545-330 \mathrm{C}-23 \mathrm{Mn}-14 \mathrm{C}-13 \mathrm{Ni}-7 \mathrm{Si}+2 \mathrm{Al}+7 \mathrm{Co}-5 \mathrm{Mo}-13 \mathrm{Cu}(w t \%)
$$

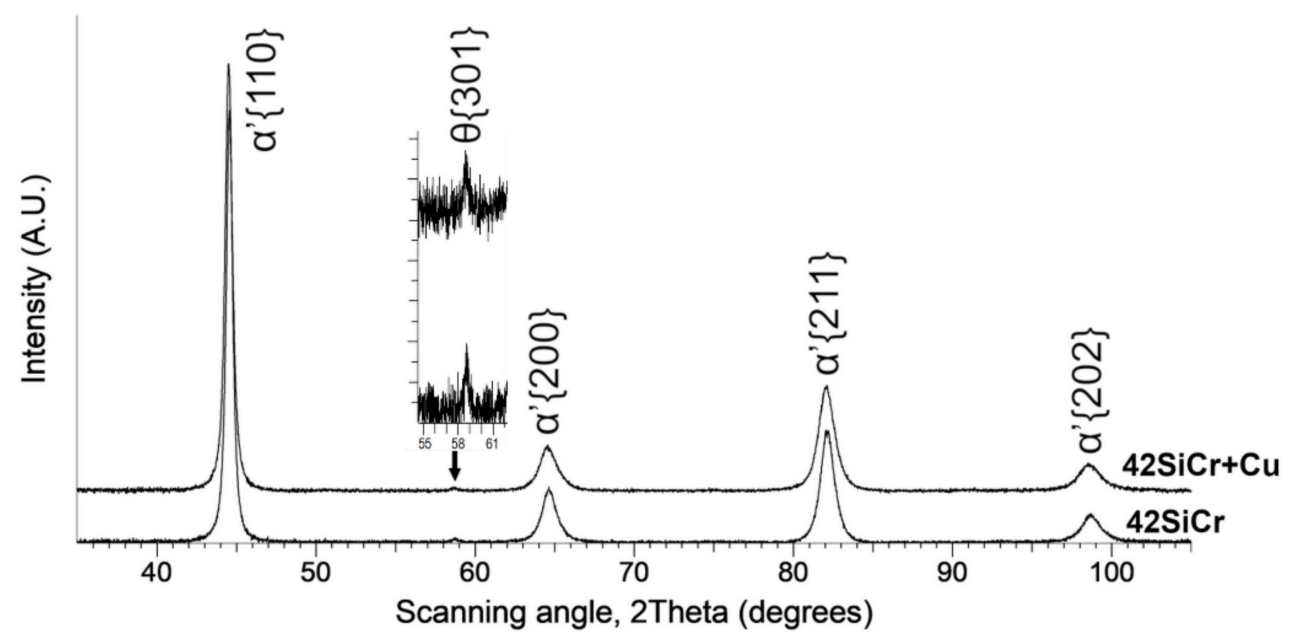

Figure 2. XRD patterns of $42 \mathrm{SiCr}$ and $42 \mathrm{SiCr}+\mathrm{Cu}$ steels after quenching. 
Microstrains (e) and dislocation density $(\rho)$ of $42 \mathrm{SiCr}$ and $42 \mathrm{SiCr}+\mathrm{Cu}$ steels after quenching and subsequent tempering, determined using XRD data in accordance with [11], are shown in Figure 3. Note that the found high value of the $\rho$ in studied steels after quenching corresponds to the result [10] on the dependence of $\rho$ on the silicon content. With an increase in the tempering temperature to $500^{\circ} \mathrm{C}$ both $e$ and $\rho$ for $42 \mathrm{SiCr}$ and $42 \mathrm{SiCr}$ $+\mathrm{Cu}$ steels decreased significantly, i.e., almost by 7 and 6 times, respectively.

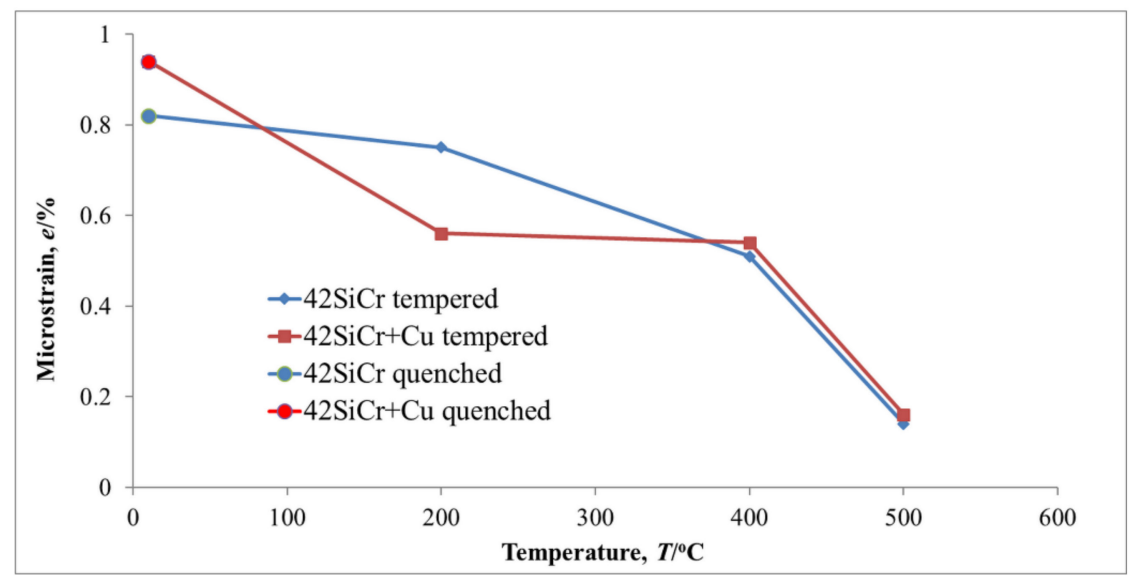

(a)

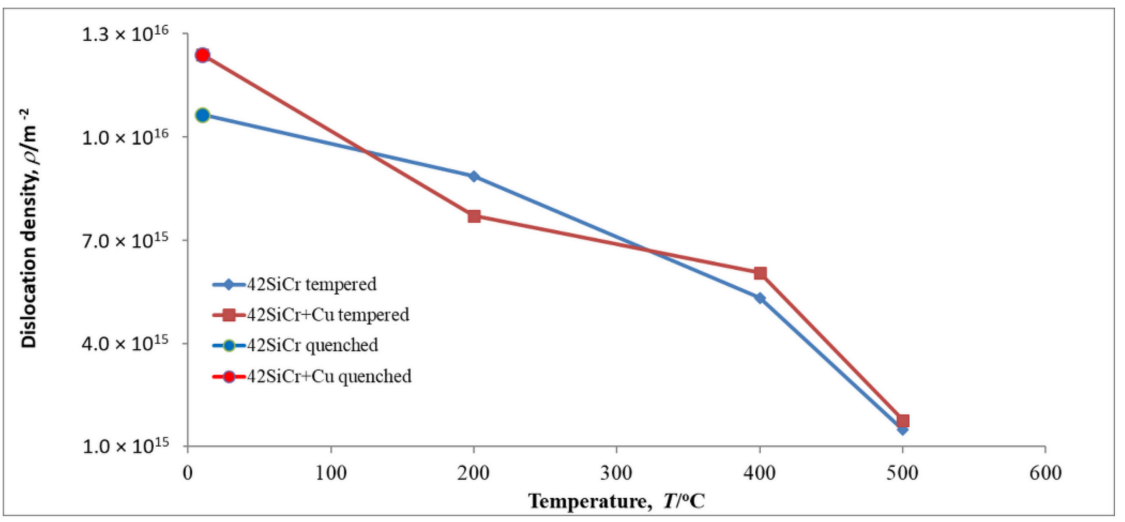

(b)

Figure 3. Variation in microstrain $e(\mathbf{a})$ and dislocation density $\rho(\mathbf{b})$ of $42 \mathrm{SiCr}$ and $42 \mathrm{SiCr}+\mathrm{Cu}$ steels after quenching and then tempering for $2 \mathrm{~h}$.

\subsection{TEM Analysis}

The microstructures observed in TEM after quenching and after tempering are shown in Figures 4-10. There was close resemblance between as-quenched microstructures in $42 \mathrm{SiCr}$ and $42 \mathrm{SiCr}+\mathrm{Cu}$ steels. Figure 4 is a micrograph of $42 \mathrm{SiCr}$ steel after quenching. Lath martensite was the dominant phase. The lath thickness ranged between 100 and $500 \mu \mathrm{m}$. After subsequent tempering at $200{ }^{\circ} \mathrm{C}$ for two hours, iron-transition-carbide precipitates (indicated with black and white arrows in Figure 5) were found in the interior of the martensite laths. This carbide is normally identified as $\varepsilon$ - or $\eta$-carbide $[5,19]$. In this study, only $\varepsilon$-carbides were detected in both 722 and 822 specimens using HRTEM analysis and a fast Fourier transform (FFT). Figure 6 shows results of HRTEM-FFT analysis of the carbide particles found in 722 specimen. These precipitates of iron transition-carbides with plate-like morphology were oriented preferentially along the [010], [001] or [011] martensite direction. Similar average lengths and widths of transition $\varepsilon$ - carbides $(72.9 \mathrm{~nm}$ and $8.3 \mathrm{~nm})$ and $(72.3 \mathrm{~nm}$ and $7.2 \mathrm{~nm})$ were found in 722 specimen and 822 specimen, respectively. 


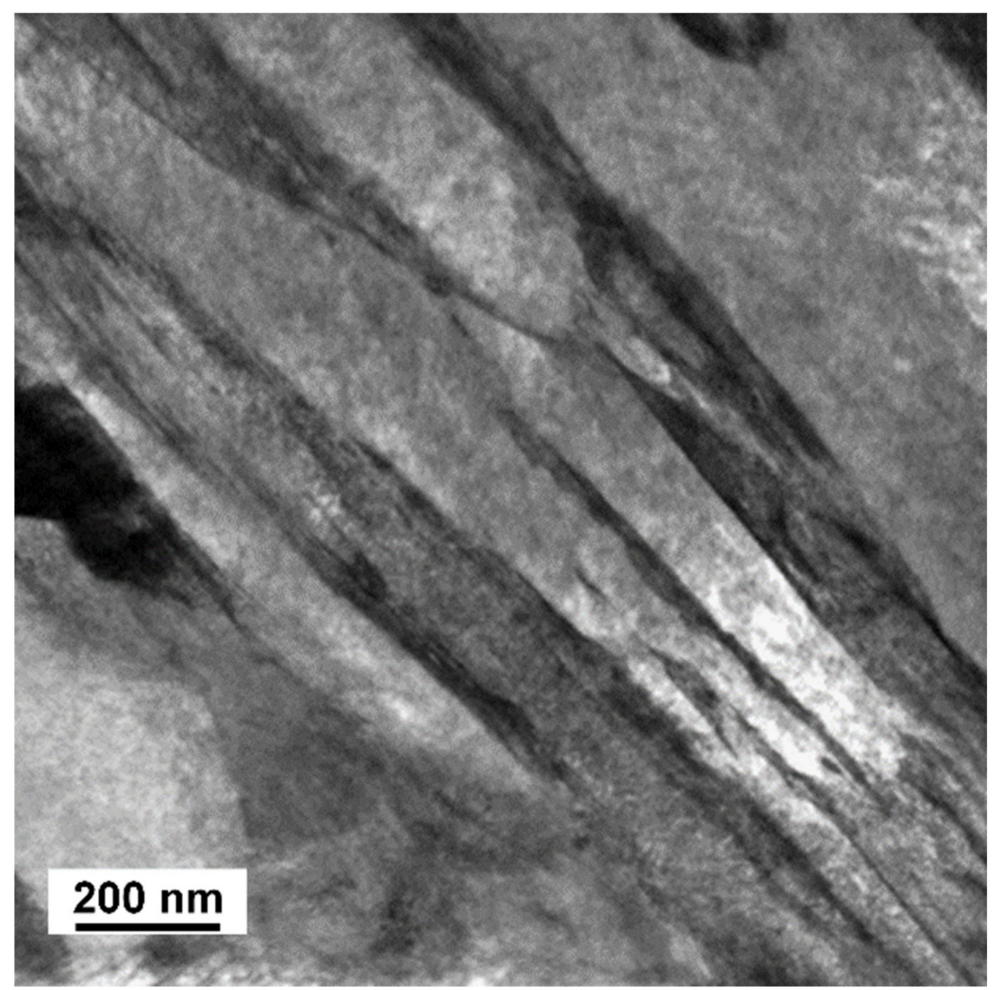

Figure 4. Lath martensite which formed during quenching of $42 \mathrm{SiCr}$ steel.

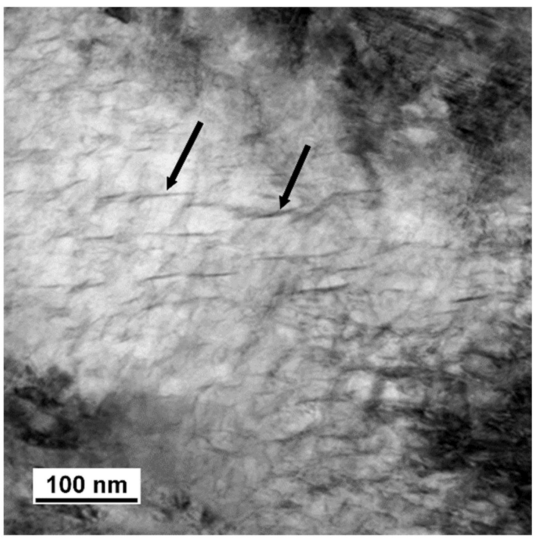

(a)

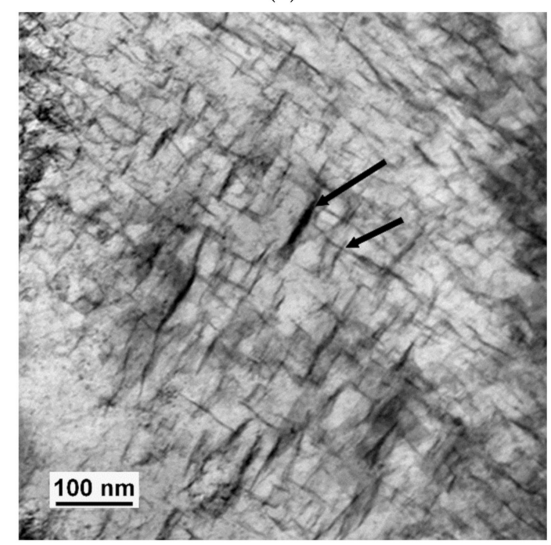

(c)

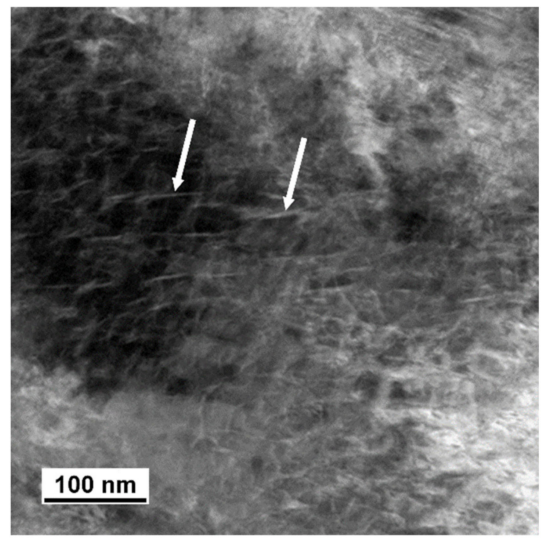

(b)

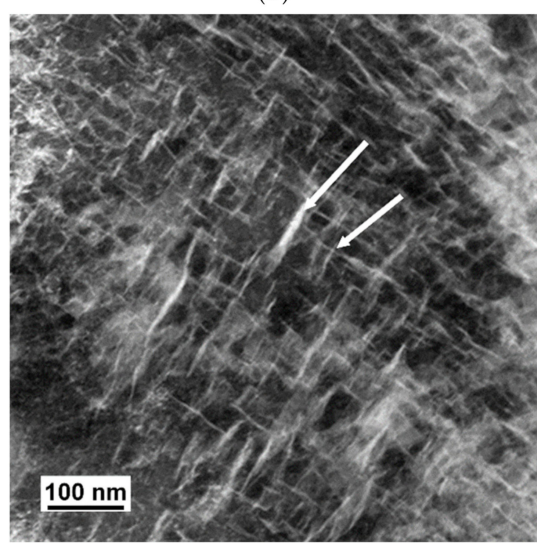

(d)

Figure 5. Iron transition carbides in lath martensite tempered at $200{ }^{\circ} \mathrm{C}$ for $2 \mathrm{~h}$ in $42 \mathrm{SiCr}$ steel; (a) bright field (BF), (b) dark field (DF); 42SiCr $+\mathrm{Cu}(\mathbf{c}) \mathrm{BF}$, (d) DF. 


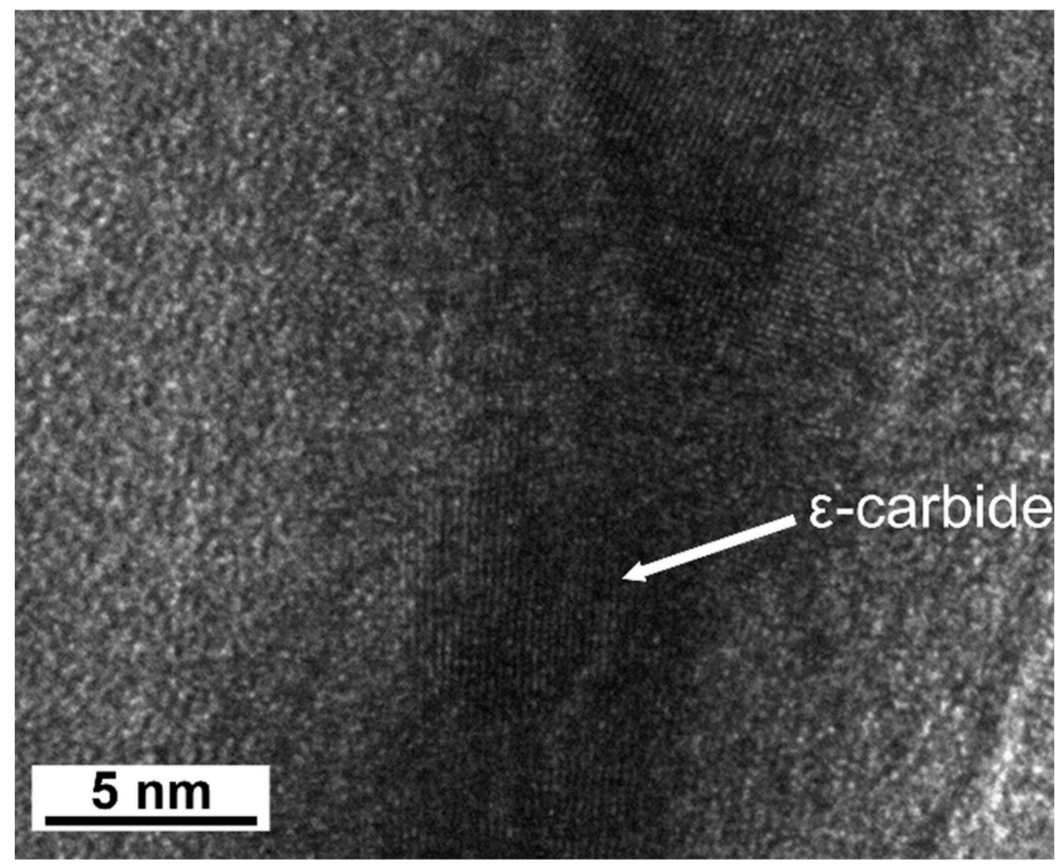

(a)

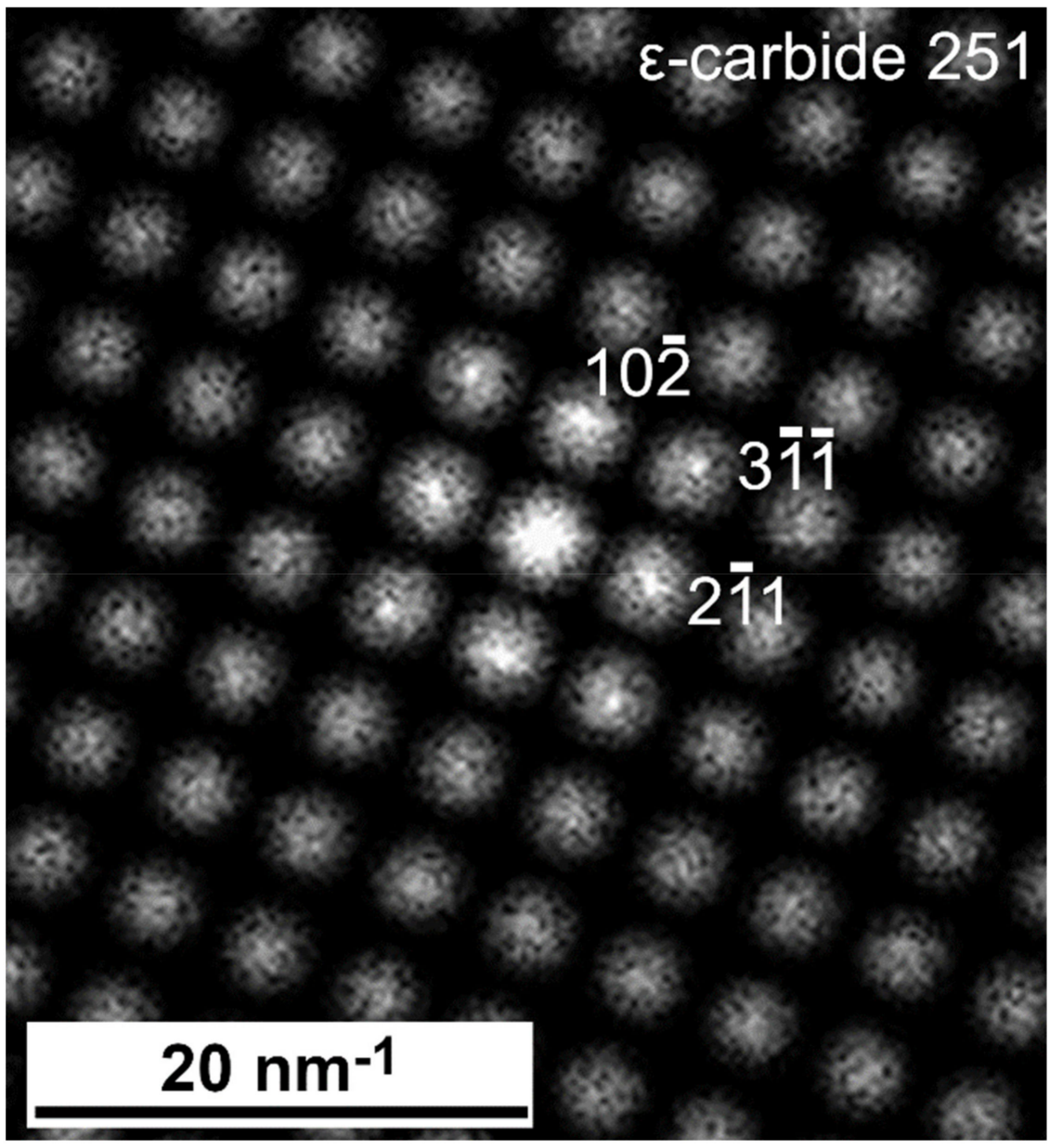

(b)

Figure 6. (a) HRTEM image of iron transition carbides in $42 \mathrm{SiCr}$ steel after tempering at $200{ }^{\circ} \mathrm{C}$, (b) A fast Fourier transform (FFT) diagram of the micrograph in (a). 


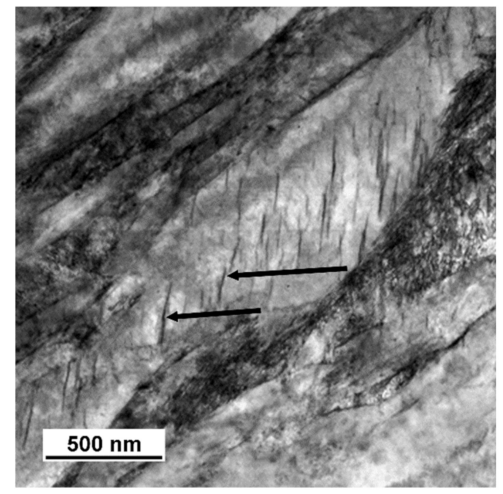

(a)

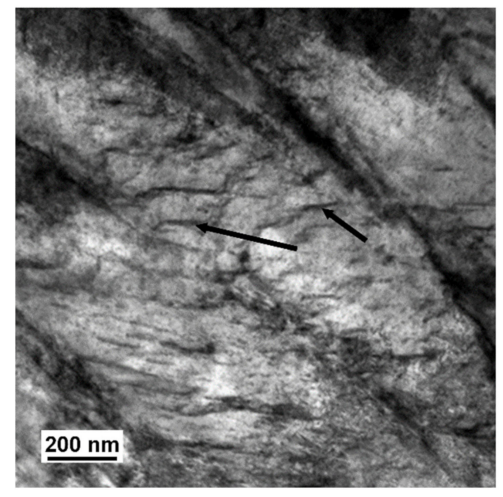

(c)

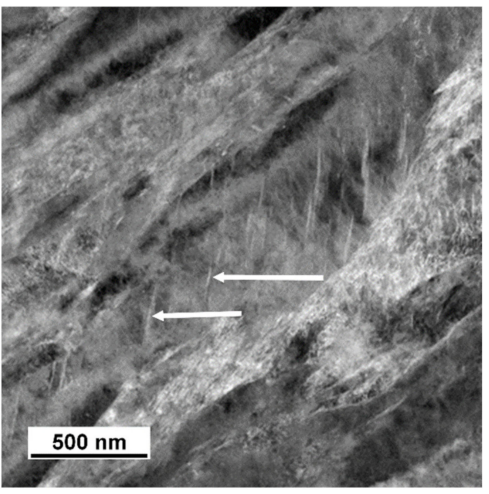

(b)

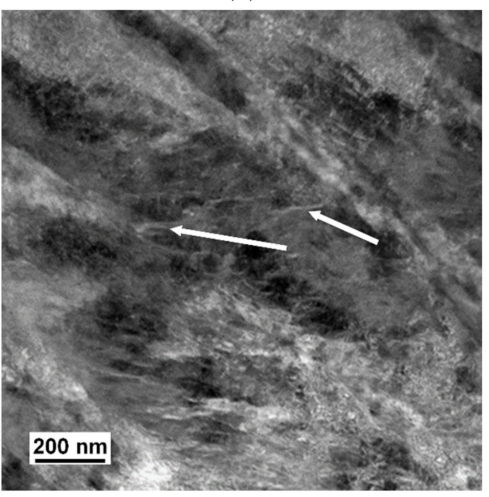

(d)

Figure 7. Iron carbides (indicated with black and white arrows) in $42 \mathrm{SiCr}$ after tempering at $400{ }^{\circ} \mathrm{C}$ (a) $\mathrm{BF}$, (b) DF and in $42 \mathrm{SiCr}+\mathrm{Cu}(\mathbf{c}) \mathrm{BF}$, (d) DF.

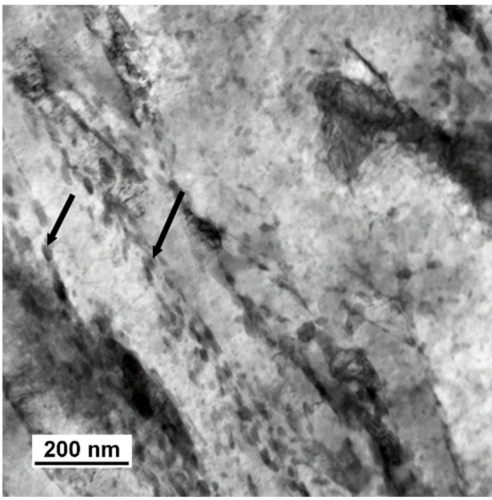

(a)

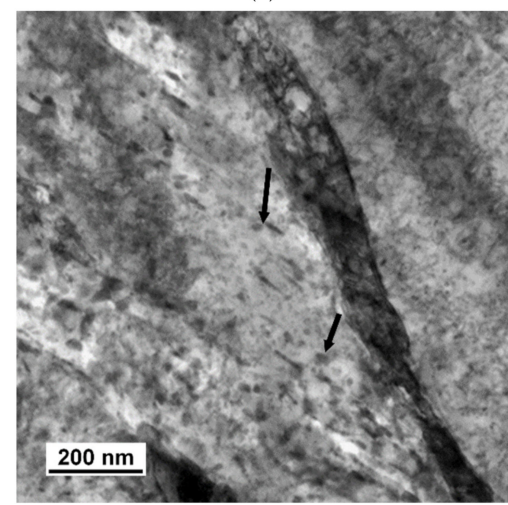

(c)

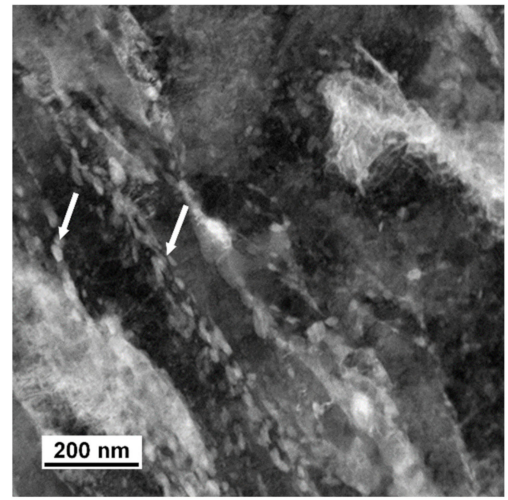

(b)

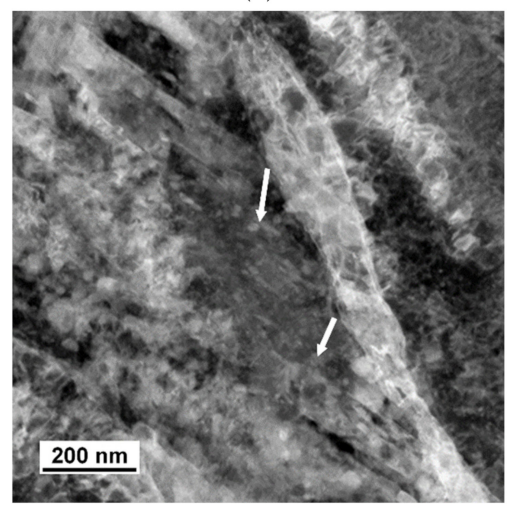

(d)

Figure 8. TEM micrograph showing cementite precipitates in martensite tempered at $500{ }^{\circ} \mathrm{C}$ in $42 \mathrm{SiCr}$ steel (a) BF, (b) DF and in $42 \mathrm{SiCr}+\mathrm{Cu}$ steel (c) BF, (d) DF. 


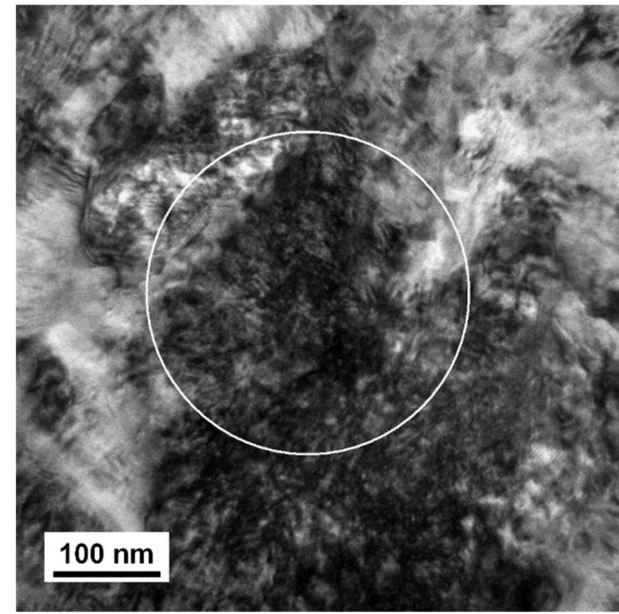

(a)

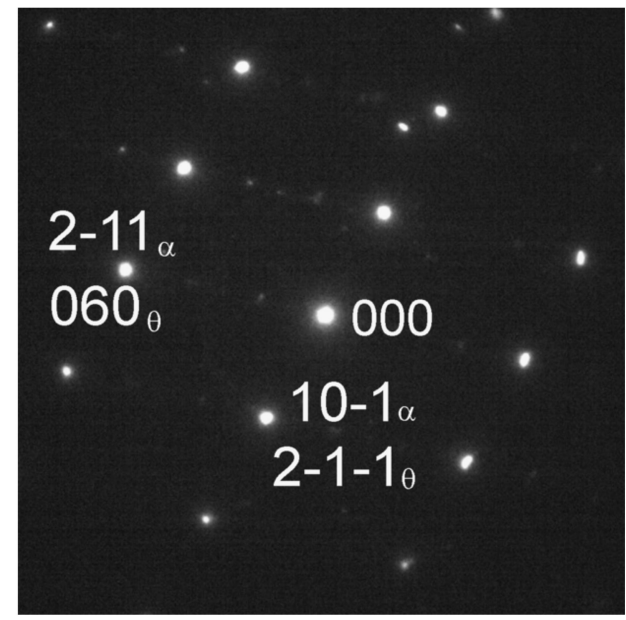

(b)

Figure 9. TEM micrograph of $42 \mathrm{SiCr}+\mathrm{Cu}$ steel tempered at $500{ }^{\circ} \mathrm{C}$ (a) bright field image, (b) SAED pattern with zone axis [131] $\alpha$. The white circle in the micrograph shows the boundary of the region for SAED analysis.

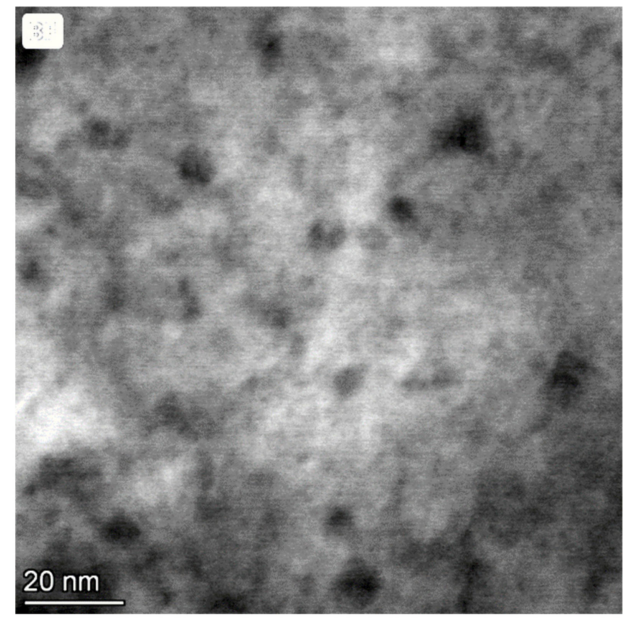

(a)

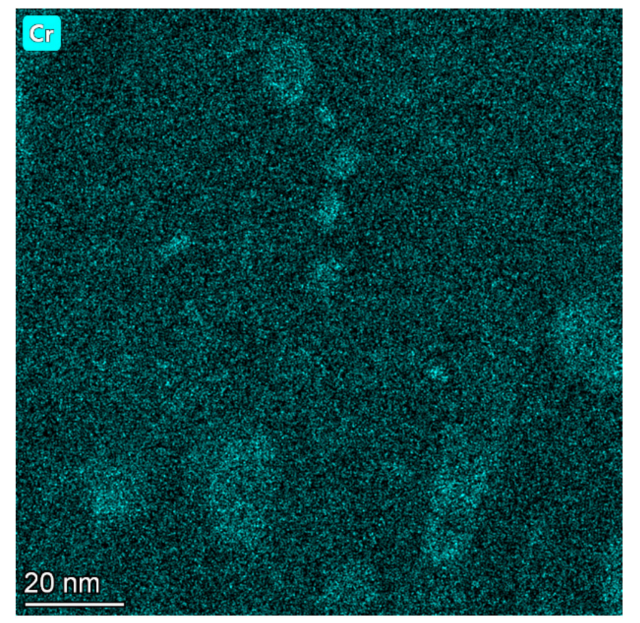

(c)

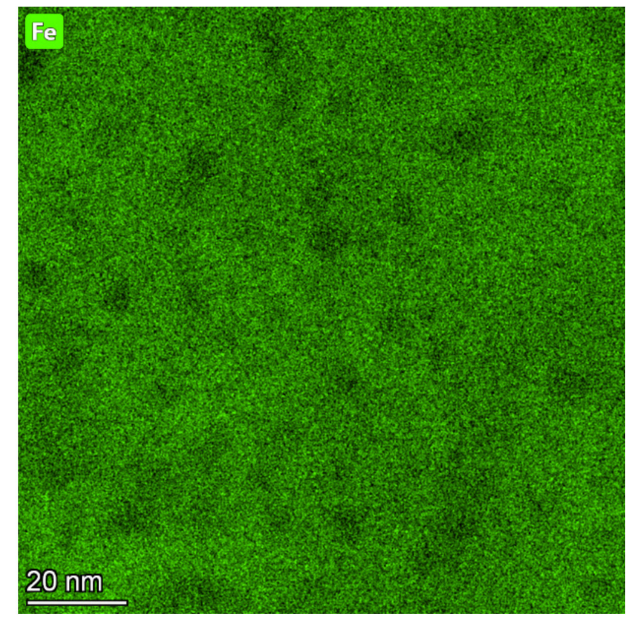

(b)

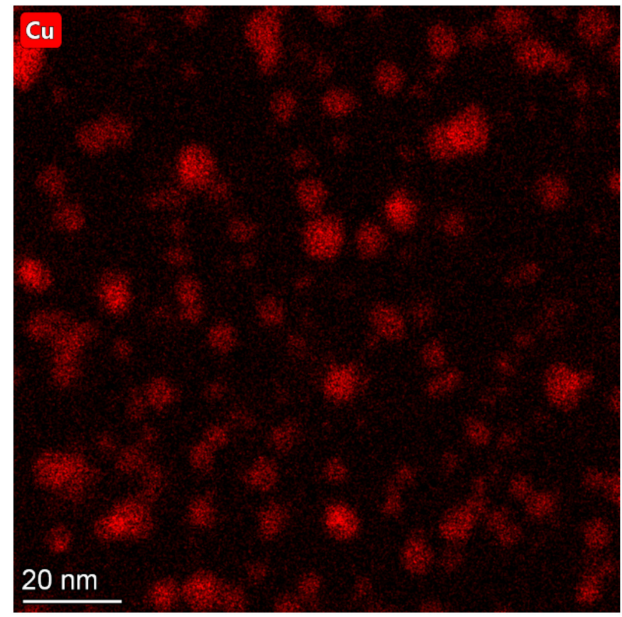

(d)

Figure 10. TEM-EDS map of chemical composition showing $\mathrm{Cu}$-rich precipitates after tempering at $500{ }^{\circ} \mathrm{C}-(\mathbf{a}) \mathrm{BF},(\mathbf{b})$ Fe map, (c) Cr map, (d) Cu map. 
Figure 7 shows a microstructure after tempering at $400{ }^{\circ} \mathrm{C}$ for two hours, which comprises tempered martensite and particles of transitional $\varepsilon$-carbide. Their average length was $99 \mathrm{~nm}$ in specimen 742 and $125 \mathrm{~nm}$ in specimen 842. The width was approximately $8 \mathrm{~nm}$ in both specimens. After the tempering temperature had been raised to $500{ }^{\circ} \mathrm{C}$, the treatment caused a change in the shape of the particles, as well as in their amount, diversity, and morphology. With increasing tempering temperature, the particles of transition carbides dissolved or transformed to another type. The new particles became more spherical. However, there were also rod-like or plate-like particles in the material. Coarser particles occupied the boundaries of tempered martensite, whereas the interior contained finer precipitates, see Figure 8. Using SAED, the particles were identified as cementite in a ferritic matrix (Figure 9). In Figure 9, strong diffraction spots of ferrite on the zone axis $[131] \alpha$, weak diffraction spots of cementite $[-102] \theta$, and orientation dependence $[131] \alpha-\mathrm{Fe} / /[-102] \theta-\mathrm{Fe} 3 \mathrm{C}$ were observed. The average length of the cementite particles was $46.5 \mathrm{~nm}$ in specimen 752 and $48.1 \mathrm{~nm}$ in specimen 852 . The steel modified with copper contained a considerably larger amount of very fine precipitates. The precipitates in it were distributed uniformly. Copper-rich precipitates ranging in size from 4 to $10 \mathrm{~nm}$ were detected, as seen in the TEM-EDS map of the chemical composition of $42 \mathrm{SiCr}+\mathrm{Cu}$ steel in Figure 10. Enrichment with $\mathrm{Cu}$ was found exactly in the iron-depleted places.

\subsection{Dilatometry}

Two contractions are found in dilatometry heating curves for $42 \mathrm{SiCr}$ and $42 \mathrm{SiCr}$ $+\mathrm{Cu}$ steels (Figure 11). The temperatures for inflection points $\left(T_{\mathrm{i}}\right)$ of these steels and steels with low silicon and chromium levels [7,8] $\left(T_{\mathrm{i}}\right.$ values for steels $[7,8]$ were taken from Figure $3 b$ in [8]) are presented in Tables 2 and 3. The inflection point for the first tempering stage indicates the precipitation of $\varepsilon$-carbides, whereas the inflection point for the second tempering stage indicates the precipitation of cementite. A very significant effect of chemical composition was found by comparing the inflection points of cementite precipitation in the present steels and in the steels studied in [8]. Note that cementite precipitates in $42 \mathrm{SiCr}$ steel are between $381{ }^{\circ} \mathrm{C}$ and $432{ }^{\circ} \mathrm{C}$ and in $42 \mathrm{SiCr}+\mathrm{Cu}$ steel are between $383{ }^{\circ} \mathrm{C}$ and $453{ }^{\circ} \mathrm{C}$ at a heating rate of $0.003 \mathrm{~K} / \mathrm{s}$ (Figure 12). Therefore, cementite can be expected in specimens 742 and 842. Tempering peaks are larger for $42 \mathrm{SiCr}+\mathrm{Cu}$ steel than for $42 \mathrm{SiCr}$ steel because a larger proportion of solute $\mathrm{C}$ atoms remain in the virgin martensite in $42 \mathrm{SiCr}+\mathrm{Cu}$ steel, which might be caused by the suppressed auto-tempering during quenching [8]. The difference in peak size corresponds to the amount of strain induced by carbide precipitation. This value decreased with increasing heating rate from $0.5 \mathrm{~K} / \mathrm{s}$. Higher heating rates shift the inflection point of strain for stage II tempering to higher temperature and suppress stage I tempering. The activation energy $E$ and frequency factor $\mathrm{K}_{0}$ calculated for $42 \mathrm{SiCr}$ and $42 \mathrm{SiCr}+\mathrm{Cu}$ steels and steels in $[7,8]$ using Equation (1) are presented in Tables 4 and 5. It was found that $E$ for cementite precipitation is very sensitive to the content of silicon and chromium. There is a weak dependence of $E$ for $\varepsilon$ carbide precipitation on $\mathrm{Si}$ and $\mathrm{Cr}$ content in the studied steels and the steels studied in $[7,8]$. The frequency factor for cementite precipitation was not found to be highly sensitive to chemical composition of steels. However, when it comes to precipitation of $\varepsilon$-carbide in steels $42 \mathrm{SiCr}$ and $42 \mathrm{SiCr}+\mathrm{Cu}$, it is several orders of magnitude higher in comparison to steels $[7,8]$. 

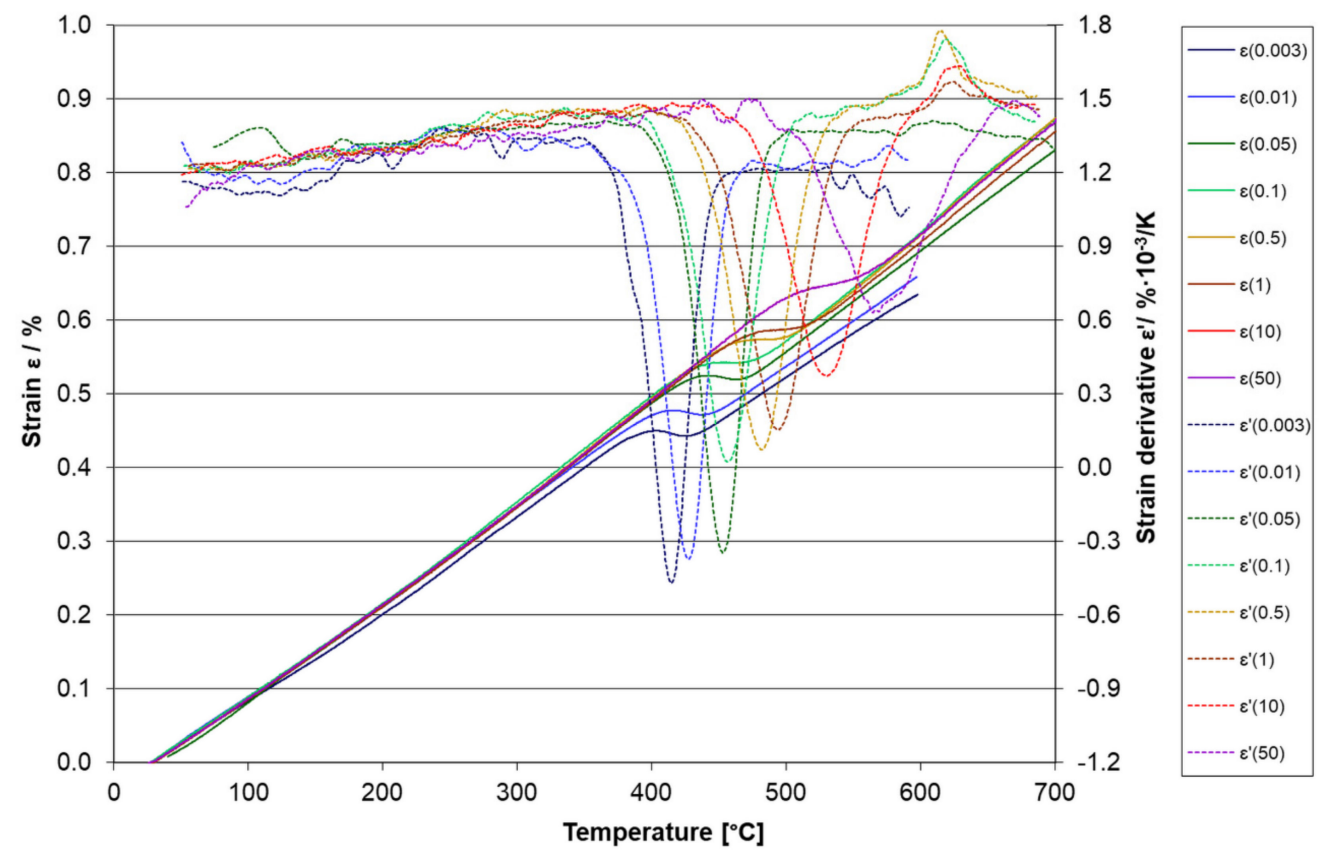

(a)

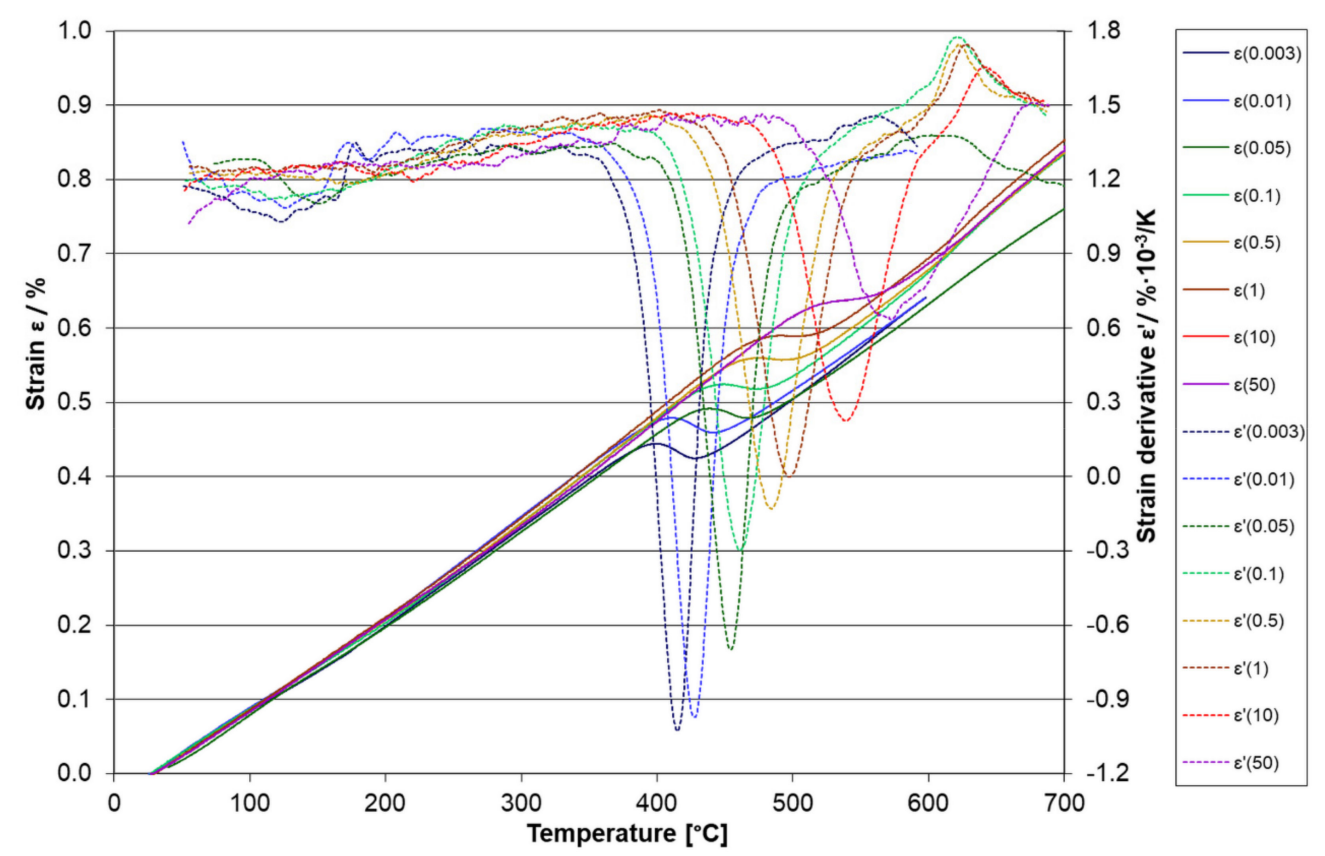

(b)

Figure 11. Thermal strain and its derivative for $42 \mathrm{SiCr}$ steel (a) and $42 \mathrm{SiCr}+\mathrm{Cu}$ steel (b) tempered using heating rates $\beta=0.003 \mathrm{~K} / \mathrm{s}, 0.01 \mathrm{~K} / \mathrm{s}, 0.05 \mathrm{~K} / \mathrm{s}, 0.1 \mathrm{~K} / \mathrm{s}, 0.5 \mathrm{~K} / \mathrm{s}, 1 \mathrm{~K} / \mathrm{s}, 10 \mathrm{~K} / \mathrm{s}$, and $50 \mathrm{~K} / \mathrm{s}$.

Table 2. Temperatures corresponding to inflection points $\left(T_{\mathrm{i}}\right)$ at different heating rates $(\beta)$ for stage I of tempering in the dilatometry data.

\begin{tabular}{ccccc}
\hline$\beta(\mathbf{K} / \mathbf{s})$ & $42 \mathrm{SiCr}$ & $\mathbf{4 2 S i C r}+\mathbf{C u}$ & Steel without Cu $[7,8]$ & Steel with Cu $[7,8]$ \\
\hline 0.003 & $126^{\circ} \mathrm{C}$ & $125^{\circ} \mathrm{C}$ & - & - \\
\hline 0.01 & $121^{\circ} \mathrm{C}$ & $125^{\circ} \mathrm{C}$ & - & - \\
\hline 0.05 & $142{ }^{\circ} \mathrm{C}$ & $145^{\circ} \mathrm{C}$ & - & - \\
\hline 0.1 & no observed & $131^{\circ} \mathrm{C}$ & $151^{\circ} \mathrm{C}$ & $144^{\circ} \mathrm{C}$ \\
\hline
\end{tabular}


Table 3. Temperatures corresponding to inflection points $\left(T_{i}\right)$ at different heating rates $(\beta)$ for stage II of tempering in the dilatometry data.

\begin{tabular}{|c|c|c|c|c|}
\hline$\beta(\mathrm{K} / \mathrm{s})$ & $42 \mathrm{SiCr}$ & $42 \mathrm{SiCr}+\mathrm{Cu}$ & Steel without $\mathrm{Cu}[7,8]$ & Steel with $\mathrm{Cu}[7,8]$ \\
\hline 0.003 & $414^{\circ} \mathrm{C}$ & $414^{\circ} \mathrm{C}$ & - & - \\
\hline 0.01 & $426^{\circ} \mathrm{C}$ & $427^{\circ} \mathrm{C}$ & - & - \\
\hline 0.05 & $452{ }^{\circ} \mathrm{C}$ & $453^{\circ} \mathrm{C}$ & - & - \\
\hline 0.1 & $456^{\circ} \mathrm{C}$ & $461^{\circ} \mathrm{C}$ & $300^{\circ} \mathrm{C}$ & $337^{\circ} \mathrm{C}$ \\
\hline 0.5 & $481^{\circ} \mathrm{C}$ & $484^{\circ} \mathrm{C}$ & $325^{\circ} \mathrm{C}$ & $345^{\circ} \mathrm{C}$ \\
\hline 1 & $493^{\circ} \mathrm{C}$ & $497^{\circ} \mathrm{C}$ & $328^{\circ} \mathrm{C}$ & $352^{\circ} \mathrm{C}$ \\
\hline 10 & $529^{\circ} \mathrm{C}$ & $539^{\circ} \mathrm{C}$ & $355^{\circ} \mathrm{C}$ & $391{ }^{\circ} \mathrm{C}$ \\
\hline 50 & $571^{\circ} \mathrm{C}$ & $574^{\circ} \mathrm{C}$ & $390^{\circ} \mathrm{C}$ & $416^{\circ} \mathrm{C}$ \\
\hline
\end{tabular}

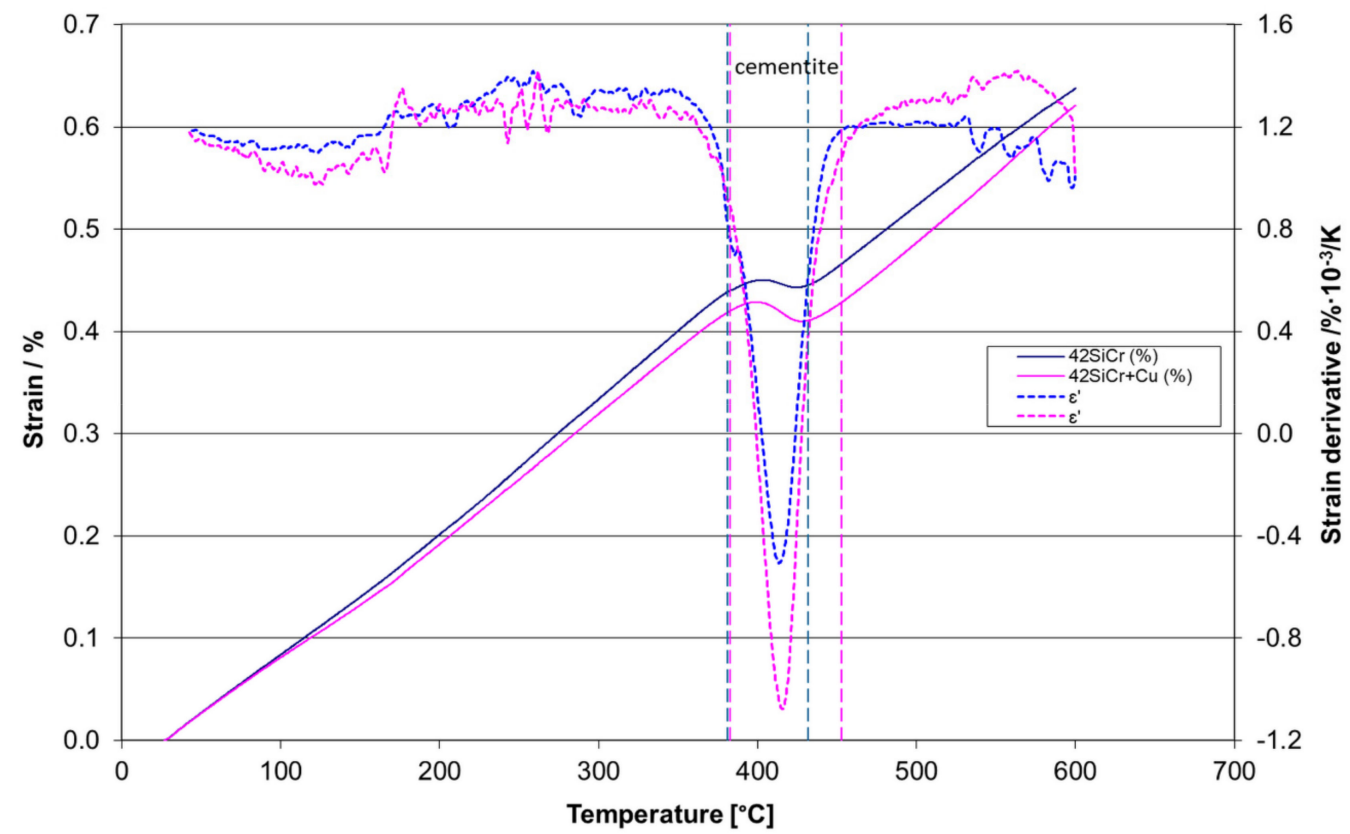

Figure 12. The temperature range for the formation of cementite in $42 \mathrm{SiCr}$ and $42 \mathrm{SiCr}+\mathrm{Cu}$ steel tempered using heating rate $\beta=0.003 \mathrm{~K} / \mathrm{s}$.

Table 4. Activation energy $E$ calculated for $42 \mathrm{SiCr}$ and $42 \mathrm{SiCr}+\mathrm{Cu}$ steels and its comparison with steels without and with $\mathrm{Cu}[7,8]$, using Equation (1).

\begin{tabular}{ccccc}
\hline Stage & $\begin{array}{c}\text { Activation Energy, } E(\mathbf{k J} / \mathbf{m o l}) \\
\text { 42SiCr Steel }\end{array}$ & $\begin{array}{c}\text { Activation Energy, } E \mathbf{~ ( k J / m o l ) ~} \\
\text { 42SiCr + Cu Steel }\end{array}$ & $\begin{array}{c}\text { Activation Energy, } E(\mathbf{k J} / \mathbf{m o l}) \\
\text { Steel without } \mathbf{C u}[7,8]\end{array}$ & $\begin{array}{c}\text { Activation Energy, } E(\mathbf{k J} / \mathbf{m o l}) \\
\text { Steel with Cu }[7,8]\end{array}$ \\
\hline I & 125 & 136 & 120 & 111 \\
\hline II & 288 & 280 & 206 & 225 \\
\hline
\end{tabular}

Table 5. Parameter $\mathrm{K}_{0}$ calculated for $42 \mathrm{SiCr}$ and $42 \mathrm{SiCr}+\mathrm{Cu}$ steels and its comparison with steels without and with $\mathrm{Cu}[7,8]$, using Equation (1).

\begin{tabular}{|c|c|c|c|c|}
\hline Stage & $\begin{array}{c}\text { Frequency Factor, } K_{0} \\
\left(\mathrm{~s}^{-1}\right) \\
\text { 42SiCr Steel }\end{array}$ & $\begin{array}{c}\text { Frequency Factor, } K_{0} \\
\qquad \begin{array}{c}\left(\mathrm{s}^{-1}\right) \\
42 \mathrm{SiCr}+\mathrm{Cu} \text { Steel }\end{array}\end{array}$ & $\begin{array}{c}\text { Frequency Factor, } K_{0}\left(\mathrm{~s}^{-1}\right) \\
\text { Steel without } \mathrm{Cu}[8]\end{array}$ & $\begin{array}{c}\text { Frequency Factor, } K_{0}\left(s^{-1}\right) \\
\text { Steel with } \mathrm{Cu}[8]\end{array}$ \\
\hline I & $1.78 \times 10^{13}$ & $7.18 \times 10^{14}$ & $4.85 \times 10^{10}$ & $9.11 \times 10^{12}$ \\
\hline II & $2.25 \times 10^{18}$ & $4.79 \times 10^{17}$ & $3.60 \times 10^{17}$ & $6.11 \times 10^{18}$ \\
\hline
\end{tabular}




\subsection{USANS Analysis}

The ex situ measured scattering curves shown in Figure 13 represent microstructural changes in the mesoscopic range after various tempering cycles followed by air cooling. The above presented TEM and dilatometry data suggest that $\varepsilon$-carbides generate the main contribution to the scattering from samples of both $42 \mathrm{SiCr}$ and $42 \mathrm{SiCr}+\mathrm{Cu}$ steels after tempering for two hours at $200{ }^{\circ} \mathrm{C}$ and $400{ }^{\circ} \mathrm{C}$ (samples 722 and 742 , as well as 822 and 842 ), although some cementite was also present in samples 742 and 842 (Figure 12). The scattering from samples tempered for two hours at $500{ }^{\circ} \mathrm{C}$ (752 and 852) occurs on cementite carbides and, in addition, on copper precipitates (in sample 852). Nevertheless, $\mathrm{Cu}$ precipitates are expected to be very small (see Figure 10d) and therefore do not contribute to the scattering in the USANS $Q$-range.

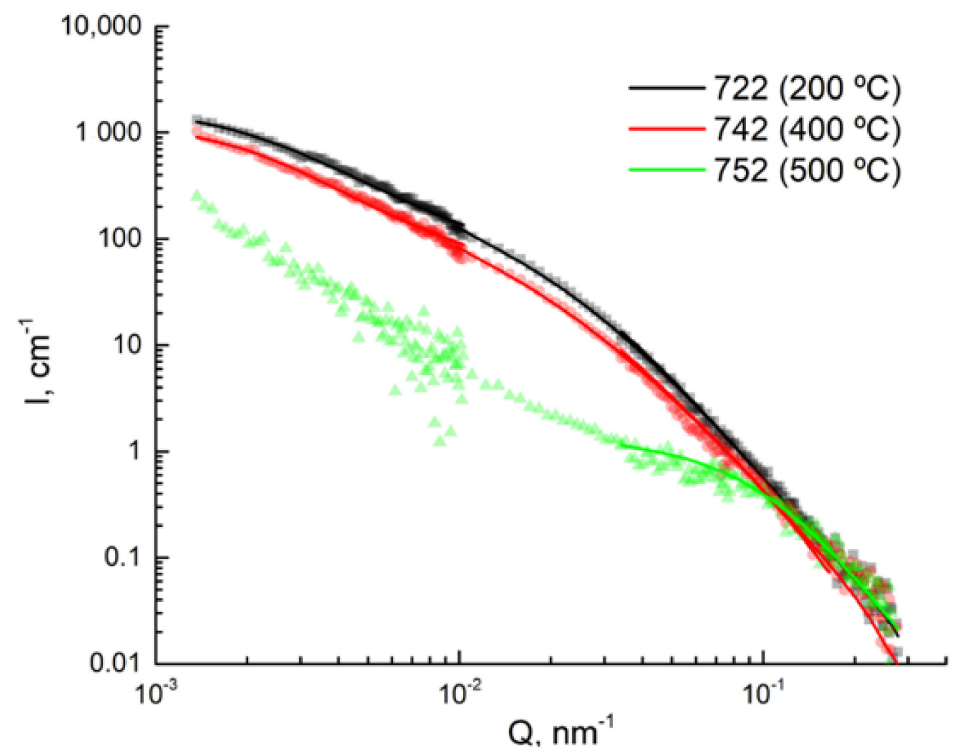

(a)

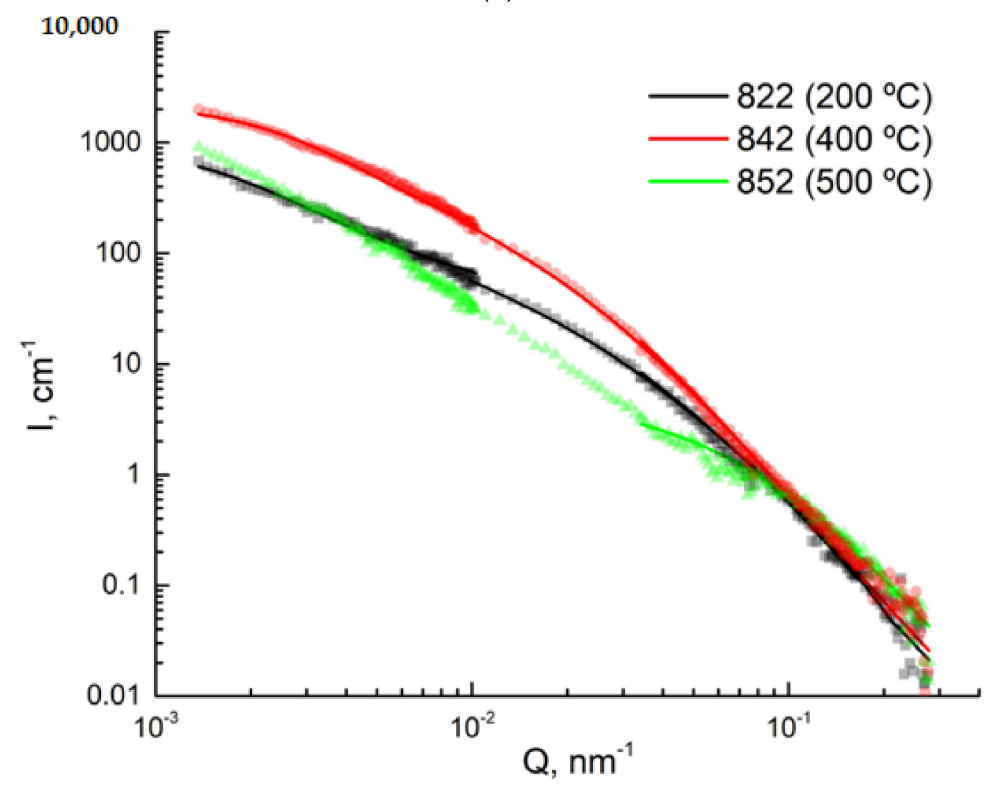

(b)

Figure 13. USANS data with fitted model curves: (a) $42 \mathrm{SiCr},(\mathbf{b}) 42 \mathrm{SiCr}+\mathrm{Cu}$.

It is remarkable that in $42 \mathrm{SiCr}$ steel the scattering cross section for $400{ }^{\circ} \mathrm{C}$-tempered sample slightly decreases when compared to the one tempered at $200^{\circ} \mathrm{C}$, whereas it is the 
opposite and more significant in $42 \mathrm{SiCr}+\mathrm{Cu}$ steel. In $42 \mathrm{SiCr}$ steel heated at $500{ }^{\circ} \mathrm{C}$, there is a significant decrease in scattering intensity across the whole $Q$-range as measured by USANS, except the largest $Q$ magnitudes-which most probably indicates the presence of small cementite precipitates. The lowest $Q$ magnitudes measured indicate severe inhomogeneity in the samples of $42 \mathrm{SiCr}+\mathrm{Cu}$ tempered at both $400{ }^{\circ} \mathrm{C}$ and at $500{ }^{\circ} \mathrm{C}$. It could be due to large cementite carbides or inclusions. Since the range of carbide sizes is certain to be broad, it is fully sufficient for obtaining a size estimate to fit lognormal distribution of spherical particles. The result of this fit (mean volume-weighted radius and lognormal distribution width parameter) is reported in Table 6.

Table 6. Model parameters obtained by fitting the USANS data. $<\mathrm{R}>$ is the mean radius and $\sigma$ is the width of the lognormal distribution.

\begin{tabular}{ccccc}
\hline Sample No. & Sample Type & Tempering Temperature & $<\mathbf{R}>\mathbf{n m}$ & $\boldsymbol{\sigma}$ \\
\hline 722 & $42 \mathrm{SiCr}$ & $200^{\circ} \mathrm{C}$ & $109 \pm 3$ & 0.71 \\
\hline 742 & $42 \mathrm{SiCr}$ & $400^{\circ} \mathrm{C}$ & $108 \pm 3$ & 0.86 \\
\hline 752 & $42 \mathrm{SiCr}$ & $500^{\circ} \mathrm{C}$ & $18.8 \pm 1.1$ & 0.42 \\
\hline 822 & $42 \mathrm{SiCr}+\mathrm{Cu}$ & $200^{\circ} \mathrm{C}$ & $82 \pm 3$ & 0.78 \\
\hline 842 & $42 \mathrm{SiCr}+\mathrm{Cu}$ & $400^{\circ} \mathrm{C}$ & $117 \pm 4$ & 0.70 \\
\hline 852 & $42 \mathrm{SiCr}+\mathrm{Cu}$ & $500^{\circ} \mathrm{C}$ & $23.1 \pm 1.4$ & 0.63 \\
\hline
\end{tabular}

The ex situ-measured SANS scattering curves are plotted in Figure 14. At first glance, the SANS curves are similar within pairs of samples (722 and 822), (742 and 842), and (752 and 852) (Figure 14). In the region of small-magnitude scattering vectors $\left(Q<0.1 \mathrm{~nm}^{-1}\right)$, the scattering intensity decreases with tempering temperature in samples of the steel without copper. An opposite trend which is seen in samples with copper tempered at $400{ }^{\circ} \mathrm{C}$ and $500{ }^{\circ} \mathrm{C}$ at larger $Q$ magnitude may have been caused by the occurrence of copper precipitates, according to $[8,20,21]$. The evolution of copper precipitates was explored by comparing the SANS magnetic scattering for samples with and without $\mathrm{Cu}$ tempered at the same temperatures (see Figure 15). It was assumed that the difference in the levels of silicon and chromium in $42 \mathrm{SiCr}$ and $42 \mathrm{SiCr}+\mathrm{Cu}$ steels did not significantly affect magnetic scattering.

The differences in magnetic scattering for materials with and without $\mathrm{Cu}$ became apparent for higher tempering temperatures $\left(400^{\circ} \mathrm{C}\right.$ and $\left.500^{\circ} \mathrm{C}\right)$. The curves were fitted using SASfit software [22]. Log-normal distributions of spherical particles were used for fitting the difference between the corresponding samples of $42 \mathrm{SiCr}$ and $42 \mathrm{SiCr}+\mathrm{Cu}$ steels. The magnetic scattering contrast for the model was estimated by calculating the magnetic scattering length density (SLD) of iron, SLD $=5.1 \cdot 1010 \mathrm{~cm}^{-2}$ because copper particles are fully nonmagnetic (SLD $=0$ ). The fitted size distributions of spherical particles weighted by volume are shown in Figure 16. The integrals over the size distributions provide the total volume fractions of copper precipitates: $\mathrm{v}^{400}=0.33 \%$ for the sample tempered at $400{ }^{\circ} \mathrm{C}$ (sample 842) and $v^{500}=1.35 \%$ for $500{ }^{\circ} \mathrm{C}$ (sample 852), respectively. The resulting values may be slightly lower than the actual ones since they were close to the instrumental resolution limit, especially with sample 842 . The mean radii of nanoparticles $<\mathrm{R}>_{V}=0.8 \mathrm{~nm}$ for sample 842 and $\left\langle\mathrm{R}>_{V}=4.1 \mathrm{~nm}\right.$ for sample 852 were found from the fitted volume weighted size distributions (Table 7) [23]. 


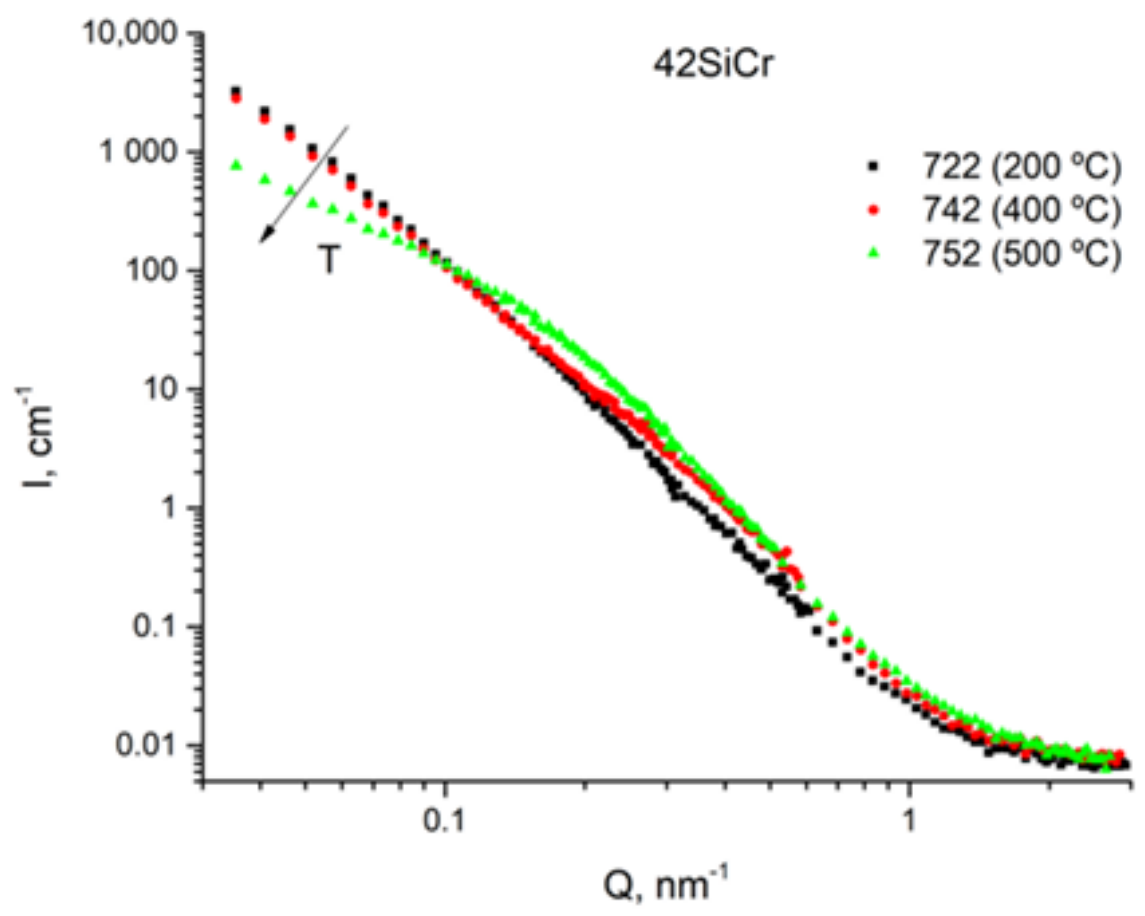

(a)

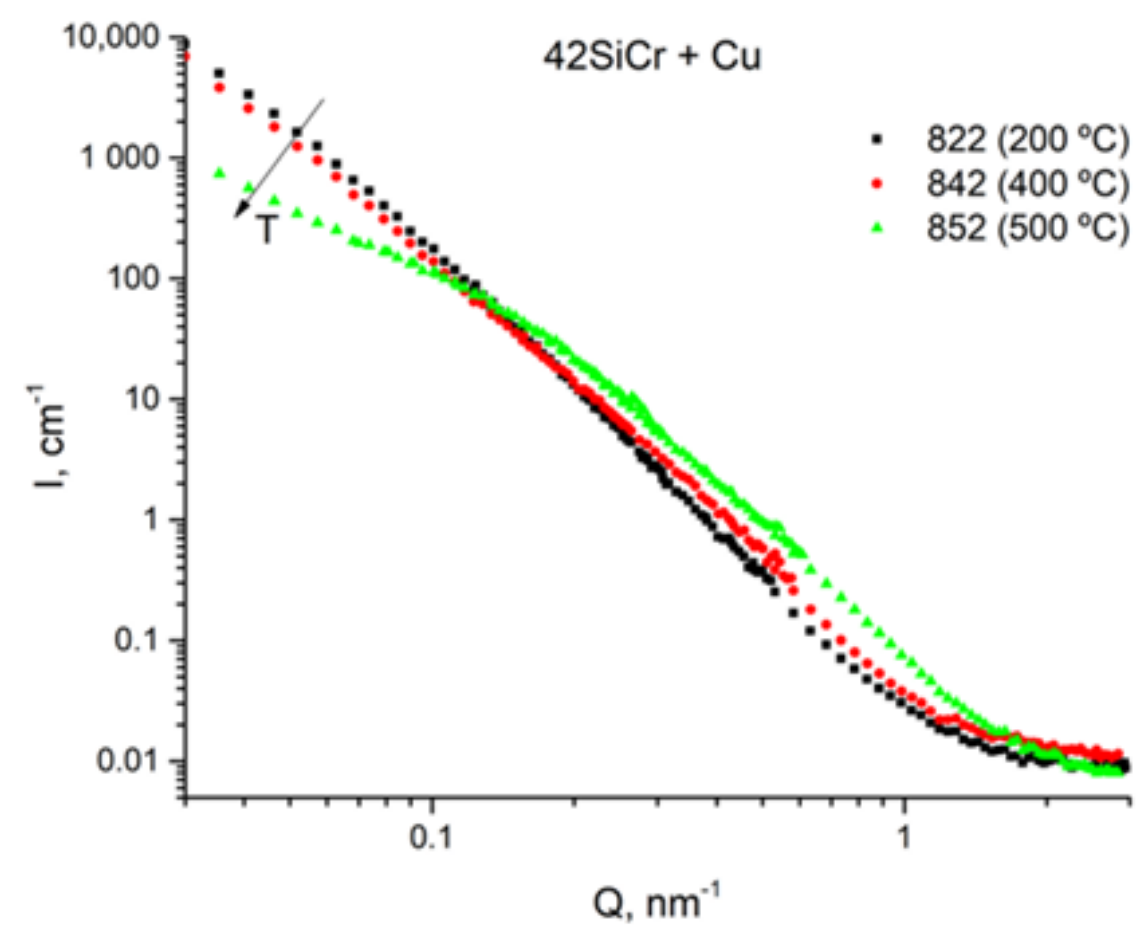

(b)

Figure 14. SANS curves for $42 \mathrm{SiCr}$ steel (a) and for $42 \mathrm{SiCr}+\mathrm{Cu}$ steel (b). 


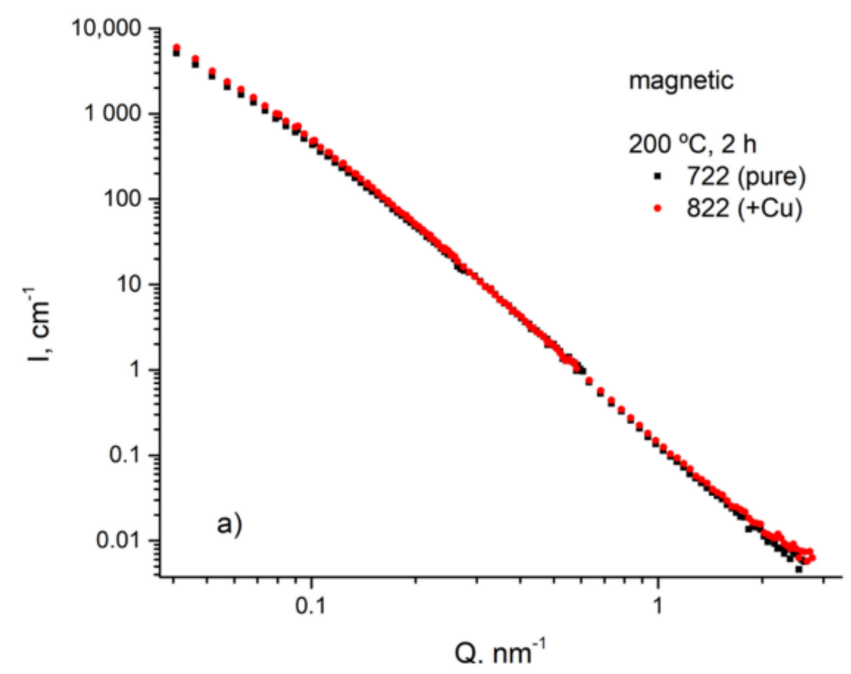

(a)

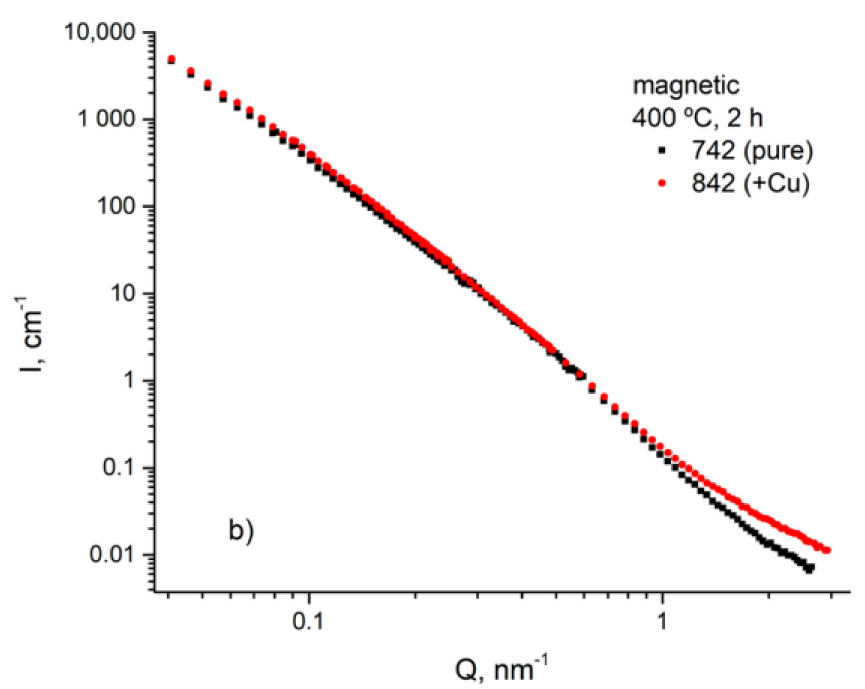

(b)

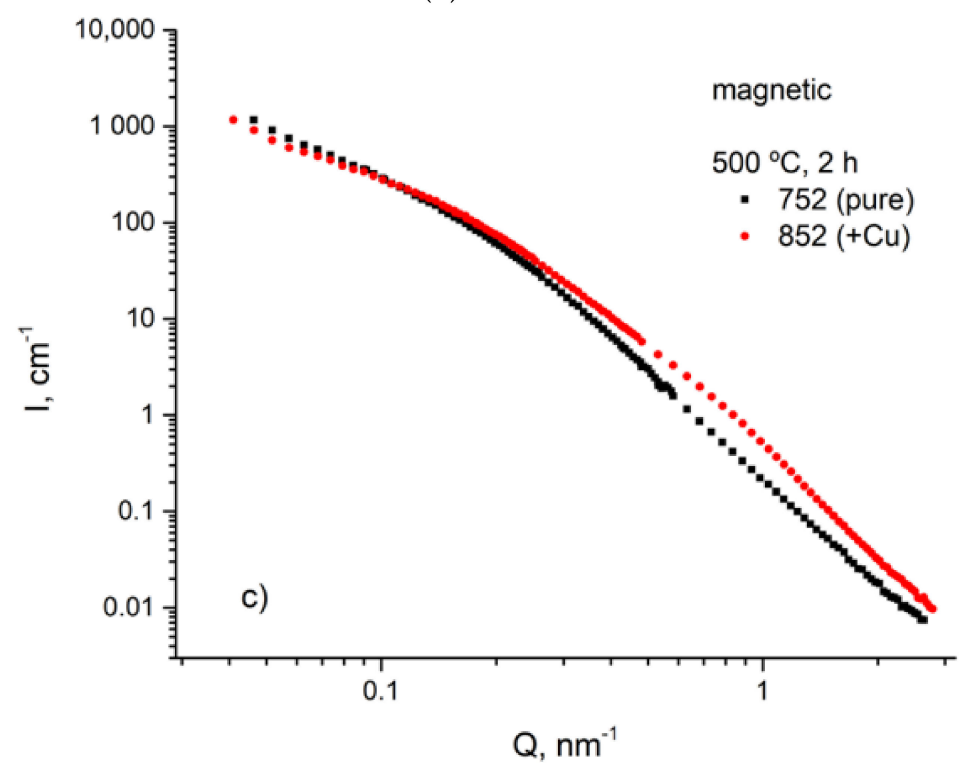

(c)

Figure 15. Magnetic SANS curves for samples tempered at $200{ }^{\circ} \mathrm{C}(\mathbf{a}), 400{ }^{\circ} \mathrm{C}(\mathbf{b})$, and $500{ }^{\circ} \mathrm{C}$ (c) (42SiCr steel-black squares, $42 \mathrm{SiCr}+\mathrm{Cu}$ steel-red circles). 


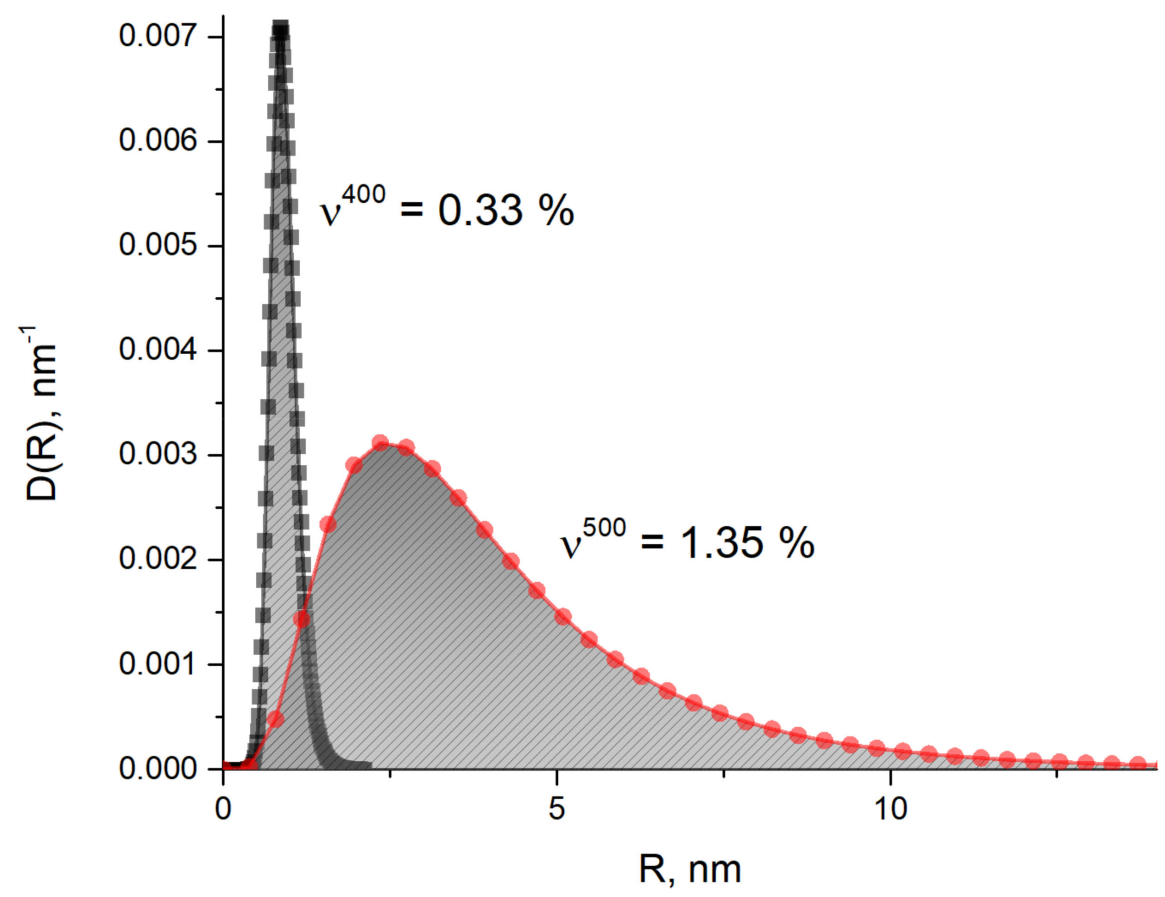

Figure 16. Volume weighted size distribution of $\mathrm{Cu}$ nanoparticles as fitted using magnetic SANS.

Table 7. Fitted parameters of magnetic scattering.

\begin{tabular}{cccccc}
\hline & $\mathbf{T}^{\circ}{ }^{\circ} \mathbf{C}$ & $\mu, \mathbf{n m}$ & $\sigma, \mathbf{n m}$ & $<R>\mathrm{V}, \mathbf{n m}$ & $v, \%$ \\
\hline $842-742$ & 400 & 0.78 & 0.21 & 0.79 & 0.33 \\
\hline $852-752$ & 500 & 1.22 & 0.59 & 4.10 & 1.35 \\
\hline
\end{tabular}

\section{Discussion}

\subsection{Phase and Microstructure Analysis}

The phase compositions of $42 \mathrm{SiCr}$ and $42 \mathrm{SiCr}+\mathrm{Cu}$ steels were determined using data from XRD, TEM, SANS, and dilatometry. Lath martensite was the dominant phase in both steels after quenching, according to TEM data. In addition, XRD analysis showed that some cementite was present in both steels even after quenching, which was due to what is referred to as auto-tempering. No retained austenite was found by XRD, which is in agreement with the relatively high martensite start temperatures: $368.4{ }^{\circ} \mathrm{C}$ for $42 \mathrm{SiCr}$ steel and $338.6^{\circ} \mathrm{C}$ for $42 \mathrm{SiCr}+\mathrm{Cu}$ steel. According to TEM observation and dilatometry, $\varepsilon$-carbides formed in $42 \mathrm{SiCr}$ and $42 \mathrm{SiCr}+\mathrm{Cu}$ steels as a result of isothermal tempering at $200^{\circ} \mathrm{C}$ and $400^{\circ} \mathrm{C}$, as well as non-isothermal tempering with temperatures of inflection points in the range of $121-145^{\circ} \mathrm{C}$. The latter is similar to the data obtained for the steels in $[7,8]$. Cementite particles formed in $42 \mathrm{SiCr}$ and $42 \mathrm{SiCr}+\mathrm{Cu}$ steels as a result of nonisothermal tempering with temperatures of inflection points in the range of $414-574{ }^{\circ} \mathrm{C}$, whereas a range of $300-416{ }^{\circ} \mathrm{C}$ was found in the steels in $[7,8]$. Therefore, it can be argued that the addition of $\mathrm{Si}$ slightly alters the kinetics of formation of $\varepsilon$-carbides but significantly affects the kinetics of cementite formation in $42 \mathrm{SiCr}$ and $42 \mathrm{SiCr}+\mathrm{Cu}$ steels, in which the $\mathrm{Si}$ content is almost $2 \mathrm{wt} \%$ higher than in steels in $[7,8]$. The physical basis of this impact of silicon is the formation of a Si-rich layer that slows down the growth of cementite outside in the iron matrix [9]. The segregation effect associated with the rejection of $\mathrm{Cr}$ atoms into cementite [9] was obviously weaker than the Si effects in the present steels, although the $\mathrm{Cr}$ content in $42 \mathrm{SiCr}$ and $42 \mathrm{SiCr}+\mathrm{Cu}$ is about $1 \mathrm{wt} \%$ higher than in steels reported in $[7,8]$. The microstructure of $42 \mathrm{SiCr}$ and $42 \mathrm{SiCr}+\mathrm{Cu}$ after isothermal tempering at $50{ }^{\circ} \mathrm{C}$ contains cementite particles in $\alpha$-iron matrix. In addition, there are $\mathrm{Cu}$-precipitates in $42 \mathrm{SiCr}+\mathrm{Cu}$ steel, according to TEM-EDS and SANS data. The tempering peaks are larger for $42 \mathrm{SiCr}+$ 
$\mathrm{Cu}$ steel than for $42 \mathrm{SiCr}$ steel, which indicates that the amount of strain caused by carbide precipitation depends on the $\mathrm{Cu}$ content. $\mathrm{Cu}$ atoms suppressed auto-tempering during quenching and thus caused more carbon atoms to remain in virgin martensite. Isothermal tempering at $400{ }^{\circ} \mathrm{C}$ leads to the formation of cementite particles in both $42 \mathrm{SiCr}$ and $42 \mathrm{SiCr}$ $+\mathrm{Cu}$ steels, according to dilatometry data, as well as to formation of $\mathrm{Cu}$ precipitates in $42 \mathrm{SiCr}+\mathrm{Cu}$ steel, according to SANS data. Note that $\mathrm{Cu}$ precipitation was not found in steels $[7,8]$ for tempering at $400{ }^{\circ} \mathrm{C}$.

\subsection{Activation Energy of Carbides}

The activation energies for transformation of carbides were calculated from dilatometry data, i.e., temperatures of inflection points for a set of heating rates using Equation (1). The activation energy for precipitation of $\varepsilon$-carbides found for the $42 \mathrm{SiCr}$ steel $(125 \mathrm{~kJ} / \mathrm{mol})$ is similar to that for the $\mathrm{Cu}$-free steel $[7,8]$ and lies between the activation energy for the volume diffusion of $C$ atoms $(80 \mathrm{~kJ} / \mathrm{mol})$ in the martensitic matrix and the value of activation energy for the diffusion of $\mathrm{Fe}$ atoms $(134 \mathrm{~kJ} / \mathrm{mol})$ along the dislocation lines in the matrix of bcc iron [24]. The activation energy for precipitation of $\varepsilon$-carbides in the $42 \mathrm{SiCr}+$ $\mathrm{Cu}$ steel was $136 \mathrm{~kJ} / \mathrm{mol}$ which is higher than for the $\mathrm{Cu}$-bearing steel in $[7,8](111 \mathrm{~kJ} / \mathrm{mol})$. The activation energies for the precipitation of cementite particles in $42 \mathrm{SiCr}$ and $42 \mathrm{SiCr}$ + Cu steels $(288 \mathrm{~kJ} / \mathrm{mol}$ and $280 \mathrm{~kJ} / \mathrm{mol})$ exceed those for steels [7,8] $(206 \mathrm{~kJ} / \mathrm{mol}$ and $225 \mathrm{~kJ} / \mathrm{mol}$ ), but are not very far from the activation energy for volume diffusion of Fe in bcc iron $(251 \mathrm{~kJ} / \mathrm{mol})$ [25]. The above-mentioned increase in the activation energy may be caused by the effect of $\mathrm{Si}$ on the activation energy for self-diffusivity of Fe in the matrix of the steels studied in a manner similar to that found in [26].

\subsection{Mechanism of Epsilon-Carbide and Cementite Formation}

The activation energies found above suggest that the mechanism of carbide precipitation in the steels under investigation is similar to that in steels $[7,8]$ in $[8,12]$ : the diffusion of Fe atoms along the dislocation lines controls the reaction during the formation of $\varepsilon$-carbides in both $42 \mathrm{SiCr}$ and $42 \mathrm{SiCr}+\mathrm{Cu}$ steels, whereas cementite particles form on the dislocation lines due to the dissolution $\varepsilon$-carbides and then their growth is controlled by the volume diffusion of Fe atoms. Thus, it can be concluded that a simultaneous increase in the content of the anti-segregating element $\mathrm{Si}$ from $0.21 \mathrm{wt} \%$ up to $2.40 \mathrm{wt} \%$, the segregating element $\mathrm{Cr}$ from $0.03 \mathrm{wt} \%$ up to $1.34 \mathrm{wt} \%$ and $\mathrm{Cu}$ from $0 \mathrm{wt} \%$ to $1.5 \mathrm{wt} \%$, with a decrease in C level from 0.44 to $0.40 \mathrm{wt} \%$ does not qualitatively change the mechanism of carbide formation induced by tempering. There is an opposite change in the USANS scattering cross section with the tempering temperature increasing from $200^{\circ} \mathrm{C}$ to $400{ }^{\circ} \mathrm{C}$ in $42 \mathrm{SiCr}$ and $42 \mathrm{SiCr}+$ $\mathrm{Cu}$ steels (Figure 13). The reason may be the effect of $\mathrm{Cu}$ described in [8] where a larger amount of solute $\mathrm{C}$ atoms remain in the virgin martensite of $42 \mathrm{SiCr}+\mathrm{Cu}$ steel, which could be caused by the suppressed auto-tempering during quenching. The latter leads to additional precipitation of carbides in $42 \mathrm{SiCr}+\mathrm{Cu}$ steel in comparison with $42 \mathrm{SiCr}$ steel.

\subsection{Size and Morphology of Carbides}

The size and morphology of carbides were determined using TEM and USANS. According to TEM data, $\varepsilon$-carbides exhibit a similar mean length of about $70 \mathrm{~nm}$ and similar mean width of about $7.7 \mathrm{~nm}$ in both $42 \mathrm{SiCr}$ and $42 \mathrm{SiCr}+\mathrm{Cu}$ steels after isothermal tempering at $200{ }^{\circ} \mathrm{C}$ for two hours. The mean length increases up to $99 \mathrm{~nm}$ and to $125 \mathrm{~nm}$ in $42 \mathrm{SiCr}$ and $42 \mathrm{SiCr}+\mathrm{Cu}$ steel, respectively, when tempered at $400{ }^{\circ} \mathrm{C}$ for two hours but the mean width turns out to be almost identical with isothermal tempering at $200{ }^{\circ} \mathrm{C}$. In these samples, $\varepsilon$-carbides resemble thin plates oriented perpendicular to the plane of observation. The shape of cementite particles was found to be more complex. They were rod-like, plate-like, or oval particles. Their mean size was smaller than that of $\varepsilon$-carbides. It was about of $47 \mathrm{~nm}$ for $42 \mathrm{SiCr}$ and $42 \mathrm{SiCr}+\mathrm{Cu}$ steels tempered at temperature $500{ }^{\circ} \mathrm{C}$ for two hours. The mean size (double the mean radius) of carbides is larger from USANS data than from TEM. It should be noted that USANS yields a volume weighted mean value 
whereas TEM provides number weighted mean size. For the size distribution as broad as this (see Table 6), this difference is thus fully understandable. The fit of the scattering from $\varepsilon$-carbides leads to an estimate of the mean size (volume weighted) of these carbides, which is in a reasonable agreement with the number weighted size distribution from TEM image processing. Both TEM and USANS found a similar trend in the mean carbide size with an increase in the tempering temperature from $400{ }^{\circ} \mathrm{C}$ to $500{ }^{\circ} \mathrm{C}$ and close mean sizes of these carbides in $\mathrm{FeCr}$ and $\mathrm{FeCr}+\mathrm{Cu}$ steels tempered at $500^{\circ} \mathrm{C}$. USANS can thus be recommended for characterizing carbides of mesoscopic size in these steels in case difficulties occur using TEM, for example, when examining microstructures after severe cold deformation. The data on the size of cementite particles can be useful for calculating the cementite precipitation strengthening component according to [10].

\subsection{Size and Morphology of $\mathrm{Cu}$ Particles}

The size and morphology of $\mathrm{Cu}$ particles were studied using SANS and TEM-EDS. Data were obtained on copper precipitates in $42 \mathrm{SiCr}+\mathrm{Cu}$ steel tempered at $500{ }^{\circ} \mathrm{C}$ for two hours. The precipitates have an average radius of $4.1 \mathrm{~nm}$ according to SANS and $3.7 \mathrm{~nm}$ according to volume weighted size distribution functions calculated from the number distribution function $D_{N}(R): D_{V}(R)=D_{N}(R) \times \frac{4 \pi}{3} R^{3}$, where $D_{N}(R)$ is calculated based on the TEM-EDS data presented in Figure 10. Differences in magnetic scattering between $42 \mathrm{SiCr}$ and $42 \mathrm{SiCr}+\mathrm{Cu}$ steels were not observed for the temperature of $200{ }^{\circ} \mathrm{C}$, but they emerged at higher tempering temperatures $\left(400{ }^{\circ} \mathrm{C}\right.$ and $\left.500{ }^{\circ} \mathrm{C}\right)$. Copper precipitation was reported after tempering between $400^{\circ} \mathrm{C}$ and $600^{\circ} \mathrm{C}$ [27]. This confirms the assumption about the insignificant impact of the difference between silicon and chromium contents in $42 \mathrm{SiCr}$ and $42 \mathrm{SiCr}+\mathrm{Cu}$ steels on the magnetic part of SANS. The SANS experiment complements the TEM-EDS measurements, which have a low detection limit for bcc iron (about $1.5 \mathrm{~nm}$ ). Small copper precipitates that are invisible in TEM-EDS, with a mean radius of $0.8 \mathrm{~nm}$ in sample 842 , were detected by SANS. After 2 -h tempering at $400{ }^{\circ} \mathrm{C}$, only partial nucleation of copper precipitates occurs (a fitted volume fraction is $0.33 \%$, i.e., about $1 / 5$ of the amount corresponding to the nominal $\mathrm{Cu}$ content). The mean size of the copper particles becomes five times larger $(<\mathrm{R}\rangle=4.1 \mathrm{~nm})$ for $\mathrm{T}=500^{\circ} \mathrm{C}$, and almost all $\mathrm{Cu}$ atoms enter the precipitates (the volume fraction resulting from the fit to the SANS data is $1.35 \%)$. Note that this value of the volume fraction was between the results obtained in [7] using SANS (1.6 $\mathrm{wt} \%)$ and the value from measurement of electrical resistivity $(1.0 \mathrm{wt} \%)$ for the steel in $[7,8]$ with $\mathrm{Cu}$, which was isothermally tempered at $500{ }^{\circ} \mathrm{C}$ for $10,000 \mathrm{~s}(2.8 \mathrm{~h})$. The mean size of copper particles found in our study was also close to that for the steel in $[7,8]$ isothermally tempered at $500{ }^{\circ} \mathrm{C}$ for $5700 \mathrm{~s}$. The A-ratio $=I_{m a g} / I_{n u c}+1$ calculated from the magnetic and nuclear scattering intensities $\left(I_{m a g}\right.$ and $\left.I_{n u c}\right)$ shows that the copper precipitates in the samples did not contain just copper. The averaged A-ratio was found to be 5.18 and 5.43 for samples 842 and 852 , respectively. This means that the copper precipitates in these samples were enriched in copper, but they were not pure copper precipitates (A-ratio would be equal to 1.4 for vacancy clusters, whereas it would be equal to 8.29 for pure copper precipitates [28]). Our statement about the multiple components in the copper precipitates in the present materials is consistent with the data from atom-probe tomography [29] and the results of calculation using the classical theory of nucleation [30].

\subsection{Yield Stress vs. Cu Precipitation}

The above-mentioned steep change in the size and volume fraction of copper particles correlates well with the change in yield stress, $R_{V p 0,2}$ of $42 \mathrm{SiCr}$ and $42 \mathrm{SiCr}+\mathrm{Cu}$ steels tempered at elevated temperatures (Figure 17) [31]. 


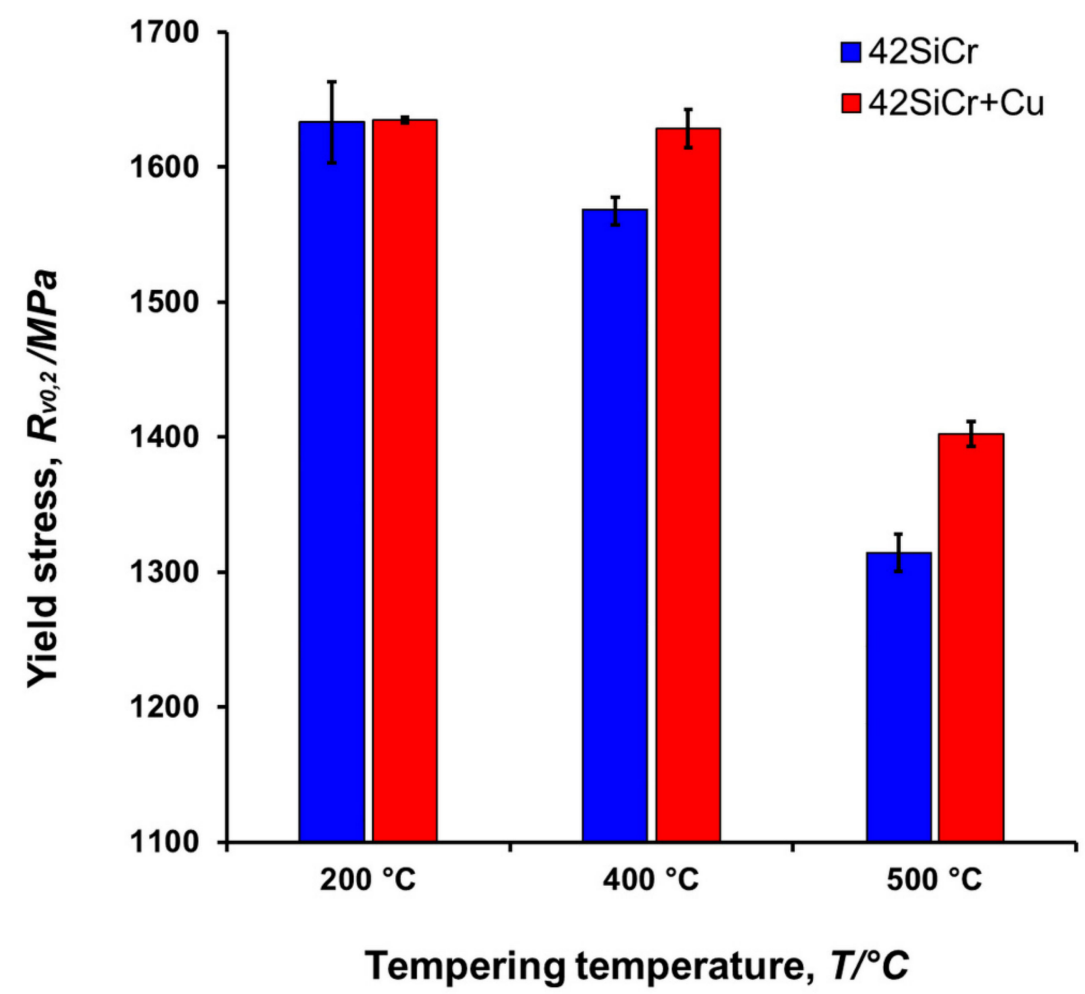

Figure 17. Yield stress $R_{V p 0,2}$ of steels $42 \mathrm{SiCr}$ and $42 \mathrm{SiCr}+\mathrm{Cu}$ tempered for two hours.

The change in yield stress $\Delta R_{V p 0,2}$ can be estimated using the Russel and Brown model [32]:

$$
\Delta R_{v p 0.2}=M G_{2}(b / L)\left\{1-\left(\frac{E_{1}}{E_{2}}\right)^{2}\right\}^{\frac{3}{4}}
$$

where

$$
\frac{E_{1}}{E_{2}}=\frac{G_{1}}{G_{2}} \frac{\log \left(\frac{R}{r_{0}}\right)}{\log \left(\frac{R_{0}}{r_{0}}\right)}+\frac{\log \left(\frac{R_{0}}{R}\right)}{\log \left(\frac{R_{0}}{r_{0}}\right)},
$$

In Equations (3) and (4), $M$ is the Taylor factor (=3.05), $G_{1}$ is the precipitate shear modulus, $G_{2}$ is the matrix shear modulus $(=83 \mathrm{GPa}), b$ is the Burger's vector $(=0.248 \mathrm{~nm})$, $r_{0}$ is the inner cutoff radius of dislocation $r_{0}(=2.5 \mathrm{~b}), R_{0}$ is the outer cutoff radius of dislocation $\left(R_{0}=2500 \mathrm{~b}\right), R$ is the radius of the precipitate $(R=0.79 \mathrm{~nm}$ and $4.1 \mathrm{~nm}$ for samples 842 and 852), $L$ is the inter-precipitate spacing, which is given by $L=1.77 \frac{R}{\sqrt{v}}$, and $v$ is the volume fraction of precipitates $v=0.0033$ and 0.0135 for samples 842 and 852) ( $L=24.7 \mathrm{~nm}$ and $62.5 \mathrm{~nm}$ for samples 842 and 852). According to [7], the chemical composition of copper precipitates changes with tempering time from a multicomponent type to almost pure copper. Therefore, the value of $G_{1}$ is not always equal to $49 \mathrm{GPa}$ which characterizes pure copper [32]. The values of $G_{1}=74.7 \mathrm{GPa}$ and $76.8 \mathrm{GPa}$ lead to calculated data from Equations (3) and (4) which are close to the experimental values $\Delta R_{V p 0,2}=61 \mathrm{MPa}$ and $89 \mathrm{MPa}$ for samples $(742,842)$ and $(752,852)$, respectively. A similar deviation of the shear modulus of copper precipitates from the shear modulus for pure copper was found in [33] $\left(G_{1}=78.0 \mathrm{GPa}\right)$.

\subsection{General Microstructure Features}

Many cementite particles of various shapes occurred in both $42 \mathrm{SiCr}$ and $42 \mathrm{SiCr}+\mathrm{Cu}$ steels during tempering between 200 and $500{ }^{\circ} \mathrm{C}$. At the same time, the microstructure of the matrix changed dramatically. The dislocation density $(\rho)$ and microstrain $(e)$ for $42 \mathrm{SiCr}$ 
and $42 \mathrm{SiCr}+\mathrm{Cu}$ steels decreased, according to XRD, almost by 7 and 6 times, respectively, due to tempering in this temperature range, which produced recovered ferrite.

\section{Conclusions}

The influence of a simultaneous increase in $\mathrm{Si}$ and $\mathrm{Cr}$ and $\mathrm{Cu}$ contents on precipitation kinetics in medium carbon steels was investigated using XRD, TEM, USANS, SANS, and dilatometry. The results obtained for 42SiCr steel (Fe-0.39C-0.65Mn-2.02Si-1.21Cr-0.09Cu) and $42 \mathrm{SiCr}+\mathrm{Cu}$ steel (Fe-0.41C-0.65Mn-2.40Si-1.34Cr-1.50Cu) were compared with those published for steel (Fe-0.44C-0.75Mn-0.25Si-0.03Cr) and steel (Fe-0.44C-0.60Mn-0.21Si$0.11 \mathrm{Cr}-1.50 \mathrm{Cu}$ ) which contain similar $\mathrm{C}, \mathrm{Mn}$, and $\mathrm{Cu}$ at similar levels as in the steels studied, but possess a lower content of Si and Cr. Several new findings on precipitation kinetics were gathered:

1. An increase in the $\mathrm{Si}$ content from $0.03 \mathrm{wt} \%$ to $2.40 \mathrm{wt} \%$ leads to the significant increase (by $80 \mathrm{~kJ} / \mathrm{mol}$ ) of the activation energy for cementite formation and slight increase of it for $\varepsilon$-carbide formation. The mechanism of copper precipitation is insensitive to $\mathrm{Si}$ and $\mathrm{Cr}$ increase. On the other hand, $\mathrm{Cu}$ addition led to an increase in the strain present in the material. However, this effect decreases with non-isothermal tempering using continuous heating with an increase in heating rate from $0.5 \mathrm{~K} / \mathrm{s}$.

2. SANS and USANS were used as complementary methods to electron imaging. Utilizing of magnetic SANS was especially efficient since it provided of size and volume parameters of the fine $\mathrm{Cu}$ precipitations.

3. The found steep change in the size and volume fraction of copper particles correlates well with the difference in yield strength, $R_{V p 0,2}$ between $42 \mathrm{SiCr}$ and $42 \mathrm{SiCr}+\mathrm{Cu}$ steels tempered at elevated temperatures. This effect can be described using the Russel-Brown model.

4. The copper precipitates in $42 \mathrm{SiCr}+\mathrm{Cu}$ steel tempered at $400{ }^{\circ} \mathrm{C}$ and $500{ }^{\circ} \mathrm{C}$ are enriched in copper, but they are not pure copper particles.

5. Many cementite carbides of various shapes formed in both $42 \mathrm{SiCr}$ and $42 \mathrm{SiCr}+\mathrm{Cu}$ steels during tempering between 200 and $500^{\circ} \mathrm{C}$. At the same time, the microstructure of the matrix changed dramatically. The dislocation density and microstrain for $42 \mathrm{SiCr}$ and $42 \mathrm{SiCr}+\mathrm{Cu}$ steels decreased almost 7 to 6 times, respectively, due to tempering in this temperature range, which produced recovered ferrite.

Author Contributions: Conceptualization, Z.N. and A.G.; investigation-heat treatment, J.K.; investigation-microstructure, P.S. (Pavel Salvetr) and J.Z.; investigation-dilatometry, P.M. and A.G.; writing-original draft, Z.N., P.S. (Pavel Salvetr), J.K., J.Z., P.M., and V.R.; writing-review and editing, A.G.; supervision. Z.N.; funding acquisition, Z.N.; SANS measurement, evaluation and interpretation: V.R., P.S. (Pavel Strunz). All authors have read and agreed to the published version of the manuscript.

Funding: This research was funded by ERDF (European Regional Development Fund) Research of advanced steels with unique properties, No. CZ02.1.01/0.0/0.0/16_019/0000836.

Institutional Review Board Statement: Not applicable.

Informed Consent Statement: Not applicable.

Data Availability Statement: The data presented in this study are available on request from the corresponding author.

Acknowledgments: The authors gratefully acknowledge the ERDF (European Regional Development Fund). MAUD diffractometer of CANAM infrastructure at NPI Řež was used for the USANS measurement. The SANS facility V4 (HZB Berlin, Germany) was employed for the SANS experiment.

Conflicts of Interest: The authors declare no conflict of interest regarding the publication of this paper. The authors alone are responsible for the content and writing of this article. 


\section{References}

1. Jirková, H.; Kučerová, L.; Mašek, B. The Effect of Chromium on Microstructure Development During Q-P Process. Mater. Today Proc. 2015, 2, S627-S630. [CrossRef]

2. Nam, W.J.; Choi, H.C. Effect of Si on mechanical properties of low alloy steels. Mater. Sci. Technol. 1999, 15, 527-530. [CrossRef]

3. Černý, I.; Mikulová, D.; Sís, J.; Mašek, B.; Jirková, H.; Malina, J. Fatigue properties of a low alloy $42 \mathrm{SiCr}$ steel heat treated by quenching and partitioning process. Procedia Eng. 2011, 10, 3310-3315. [CrossRef]

4. Morra, P.V.; Böttger, A.J.; Mittemeijer, E.J. Decomposition of iron-based martensite: A kinetic analysis by means of differential scanning calorimetry and dilatometry. J. Therm. Anal. Calorim. 2001, 64, 905-914. [CrossRef]

5. Jung, M.; Lee, S.J.; Lee, Y.K. Microstructural and dilatational changes during tempering and tempering kinetics in martensitic medium-carbon steel. Metall. Mater. Trans. A Phys. Metall. Mater. Sci. 2009, 40, 551-559. [CrossRef]

6. Primig, S.; Leitner, H. Separation of overlapping retained austenite decomposition and cementite precipitation reactions during tempering of martensitic steel by means of thermal analysis. Thermochim. Acta 2011, 526, 111-117. [CrossRef]

7. Jung, J.-G.; Jung, M.; Lee, S.-M.; Shin, E.; Shin, H.-C.; Lee, Y.-K. Cu precipitation kinetics during martensite tempering in a medium C steel. J. Alloys Compd. 2013, 553, 299-307. [CrossRef]

8. Jung, J.-G.; Jung, M.; Kang, S.; Lee, Y.-K. Precipitation behaviors of carbides and Cu during continuous heating for tempering in Cu-bearing medium C martensitic steel. J. Mater. Sci. 2014, 49, 2204-2212. [CrossRef]

9. Wu, Y.X.; Sun, W.W.; Gao, X.; Styles, M.J.; Arlazarov, A.; Hutchinson, C.R. The effect of alloying elements on cementite coarsening during martensite tempering. Acta Mater. 2020, 183, 418-437. [CrossRef]

10. Klemm-Toole, J.; Benz, J.; Vieira, I.; Clarke, A.J.; Thompson, S.W.; Findley, K.O. Strengthening mechanisms influenced by silicon content in high temperature tempered martensite and bainite. Mater. Sci. Eng. A 2020, 786, 139419. [CrossRef]

11. Peng, J.; Li, K.; Peng, J.; Pei, J.; Zhou, C. The effect of pre-strain on tensile behaviour of 316L austenitic stainless steel. Mater. Sci. Technol. 2018, 34, 547-560. [CrossRef]

12. Leiva, J.A.V.; Morales, E.V.; Villar-Cociña, E.; Donis, C.A.; Bott, I.D.S. Kinetic parameters during the tempering of low-alloy steel through the non-isothermal dilatometry. J. Mater. Sci. 2010, 45, 418-428. [CrossRef]

13. Strunz, P.; Saroun, J.; Mikula, P.; Lukás, P.; Eichhorn, F. Double-Bent-Crystal Small-Angle Neutron Scattering Setting and its Applications. J. Appl. Crystallogr. 1997, 30, 844-848. [CrossRef]

14. Keiderling, U.; Wiedenmann, A. New SANS instrument at the BER II reactor in Berlin, Germany. Phys. B Condens. Matter 1995, 213-214, 895-897. [CrossRef]

15. Wiedenmann, A. Small Angle Neutron Scattering Investigations of Magnetic Nanostructures. In Neutron Scattering from Magnetic Materials; Chatterji, T., Ed.; Elsevier: Amsterdam, The Netherlands, 2006; pp. 473-520. [CrossRef]

16. Keiderling, U. The new "BerSANS-PC" software for reduction and treatment of small angle neutron scattering data. Appl. Phys. A Mater. Sci. Process. 2002, 74, s1455-s1457. [CrossRef]

17. Šaroun, J. Evaluation of double-crystal SANS data influenced by multiple scattering. J. Appl. Crystallogr. 2000, 33, 824-828. [CrossRef]

18. Ishida, K. Calculation of the effect of alloying elements on the Ms temperature in steels. J. Alloys Compd. 1995, 220, 126-131. [CrossRef]

19. Thompson, S.W. Structural characteristics of transition-iron-carbide precipitates formed during the first stage of tempering in 4340 steel. Mater. Charact. 2015, 106, 452-462. [CrossRef]

20. He, S.M.; van Dijk, N.H.; Paladugu, M.; Schut, H.; Kohlbrecher, J.; Tichelaar, F.D.; van der Zwaag, S. In situ determination of aging precipitation in deformed Fe-Cu and Fe-Cu-B-N alloys by time-resolved small-angle neutron scattering. Phys. Rev. B 2010, 82, 174111. [CrossRef]

21. Osamura, K.; Okuda, H.; Takashima, M.; Asano, K.; Furusaka, M. Small-Angle Neutron Scattering Study of Phase Decomposition in Fe-Cu Binary Alloy. Mater. Trans. JIM 1993, 34, 305-311. [CrossRef]

22. Breßler, I.; Kohlbrecher, J.; Thünemann, A.F. SASfit: A tool for small-angle scattering data analysis using a library of analytical expressions. J. Appl. Crystallogr. 2015, 48, 1587-1598. [CrossRef]

23. Breßler, I.; Kohlbrecher, J.; Thünemann, A.F. SASfit: A comprehensive tool for small-angle scattering data analysis. arXiv 2015, (preprint). arXiv:1506.02958.

24. Cohen, M. Self-Diffusion during Plastic Deformation. Trans. Japan Inst. Met. 1970, 11, 145-151. [CrossRef]

25. Buffington, F.S.; Hirano, K.; Cohen, M. Self diffusion in iron. Acta Metall. 1961, 9, 434-439. [CrossRef]

26. Vasilyev, A.A.; Sokolov, S.F.; Kolbasnikov, N.G.; Sokolov, D.F. Effect of alloying on the self-diffusion activation energy in $\gamma$-iron. Phys. Solid State 2011, 53, 2194-2200. [CrossRef]

27. Dlouhy, J.; Podany, P.; Dzugan, J. Strengthening from Cu Addition in 0.2C-(1-2)Mn Steels during Tempering. Materials 2019, 12, 247. [CrossRef] [PubMed]

28. Solt, G.; Frisius, F.; Waeber, W.B.; Tipping, P. Irradiation induced precipitation in model alloys with systematic variation of Cu, $\mathrm{Ni}$ and P content: A small angle neutron scattering study. In Effects of Radiation on Materials: Sixteenth International Symposium, 2nd ed.; Kumar, A., Gelles, R.D., Nanstadt, R., Little, T., Eds.; ASTM International: Philadelphia, PA, USA, 1993 ; pp. 444-461.

29. Isheim, D.; Gagliano, M.S.; Fine, M.E.; Seidman, D.N. Interfacial segregation at Cu-rich precipitates in a high-strength low-carbon steel studied on a sub-nanometer scale. Acta Mater. 2006, 54, 841-849. [CrossRef] 
30. Kozeschnik, E. Thermodynamic prediction of the equilibrium chemical composition of critical nuclei: Bcc Cu precipitation in $\alpha$-Fe. Scr. Mater. 2008, 59, 1018-1021. [CrossRef]

31. Zmeko, J. New Designed Spring Steel with High Strength Values. Bachelor's Thesis, University of West Bohemia, Pilsen, Czech Republic, 2019.

32. Russell, K.C.; Brown, L. A dispersion strengthening model based on differing elastic moduli applied to the iron-copper system. Acta Metall. 1972, 20, 969-974. [CrossRef]

33. Takeuchi, T.; Kuramoto, A.; Kameda, J.; Toyama, T.; Nagai, Y.; Hasegawa, M.; Ohkubo, T.; Yoshiie, T.; Nishiyama, Y.; Onizawa, K. Effects of chemical composition and dose on microstructure evolution and hardening of neutron-irradiated reactor pressure vessel steels. J. Nucl. Mater. 2010, 402, 93-101. [CrossRef] 